\title{
Simultaneous determination of aerosol optical thickness and water-leaving radiance from multispectral measurements in coastal waters
}

\author{
Chong Shi ${ }^{1,2,3}$ and Teruyuki Nakajima ${ }^{1}$ \\ ${ }^{1}$ Japan Aerospace Exploration Agency, Earth Observation Research Center, Tsukuba, Ibaraki, Japan \\ ${ }^{2}$ Collaborative Innovation Center on Forecast and Evaluation of Meteorological Disasters, \\ Nanjing University of Information Science and Technology, Nanjing, China \\ ${ }^{3}$ Key Laboratory of Middle Atmosphere and Global Environmental Observation, Institute of Atmospheric Physics, \\ Chinese Academy of Sciences, Beijing, China
}

Correspondence: Chong Shi (shi.chong@ac.jaxa.jp) and Teruyuki Nakajima (nakajima.teruyuki@jaxa.jp)

Received: 29 September 2017 - Discussion started: 6 October 2017

Revised: 31 January 2018 - Accepted: 1 February 2018 - Published: 20 March 2018

\begin{abstract}
Retrieval of aerosol optical properties and waterleaving radiance over ocean is challenging since the latter mostly accounts for $\sim 10 \%$ of the satellite-observed signal and can be easily influenced by the atmospheric scattering. Such an effort would be more difficult in turbid coastal waters due to the existence of optically complex oceanic substances or high aerosol loading. In an effort to solve such problems, we present an optimization approach for the simultaneous determination of aerosol optical thickness (AOT) and normalized water-leaving radiance $\left(\mathrm{nL}_{\mathrm{w}}\right)$ from multispectral satellite measurements. In this algorithm, a coupled atmosphere-ocean radiative transfer model combined with a comprehensive bio-optical oceanic module is used to jointly simulate the satellite-observed reflectance at the top of atmosphere and water-leaving radiance just above the ocean surface. Then, an optimal estimation method is adopted to retrieve AOT and $\mathrm{nL}_{\mathrm{w}}$ iteratively. The algorithm is validated using Aerosol Robotic Network - Ocean Color (AERONET-OC) products selected from eight OC sites distributed over different waters, consisting of observations that covered glint and non-glint conditions from the Moderate Resolution Imaging Spectroradiometer (MODIS) instrument. Results show a good consistency between retrieved and in situ measurements at each site. It is demonstrated that more accurate AOTs are determined based on the simultaneous retrieval method, particularly in shorter wavelengths and sunglint conditions, where the averaged percentage difference (APD) of retrieved AOT is generally reduced by ap-
\end{abstract}

proximate $10 \%$ in visible bands compared with those derived from the standard atmospheric correction (AC) scheme, since all the spectral measurements can be used jointly to increase the information content in the inversion of AOT, and the wind speed is also simultaneously retrieved to compensate the specular reflectance error estimated from the rough ocean surface model. For the retrieval of $\mathrm{nL}_{\mathrm{w}}$, atmospheric overcorrection can be avoided in order to have a significant improvement of the inversion of $\mathrm{nL}_{\mathrm{w}}$ at $412 \mathrm{~nm}$. Furthermore, generally better estimates of band ratios of $\mathrm{nL}_{\mathrm{w}}(443) / \mathrm{nL}_{\mathrm{w}}(554)$ and $\mathrm{nL}_{\mathrm{w}}(488) / \mathrm{nL}_{\mathrm{w}}(554)$ are obtained using the simultaneous retrieval approach with lower root mean square errors and relative differences than those derived from the standard $\mathrm{AC}$ approach in comparison to the AERONET-OC products, as well as the APD values of retrieved $\mathrm{Chl}$ which decreased by about $5 \%$. On the other hand, the standard AC scheme yields a more accurate retrieval of $\mathrm{nL}_{\mathrm{w}}$ at $488 \mathrm{~nm}$, prompting a further optimization of the oceanic bio-optical module of the current model.

\section{Introduction}

Aerosol monitoring is indispensable for evaluating the global energy budget and material exchange (Li et al., 2009). They exert significant impacts on the radiation process through both direct and indirect effects (Boucher et al., 2013). Quantifying aerosol optical properties is also crucial for the remote 
sensing of ocean color (OC) as atmospheric backscattering, which is composed of aerosol and Rayleigh scattering, contributes a greater fraction of signals at the top of atmosphere than the spectral water-leaving radiance $\left(L_{\mathrm{w}}\right)$ from the ocean body (Gordon and Morel, 1983). Since the Rayleigh scattering can be determined at a high precision level by considering the effects of polarization, surface pressure and roughness (Gordon et al., 1988; Wang, 2002), accurate estimation of aerosols becomes particularly important for the determination of water-leaving radiance and oceanic substances.

To derive the aerosol optical properties over ocean, some approaches compare observed and precalculated reflectance at selected channels assuming that the water-leaving radiance can be neglected or empirically estimated. For example, the Moderate Resolution Imaging Spectroradiometer (MODIS) Collection 5 operational over-ocean algorithm specifies zero water-leaving radiance for all except at $550 \mathrm{~nm}$ where a value of reflectance 0.005 is assumed (Remer et al., 2005). When evaluating the influence of aerosols on the remote sensing of ocean color, other approaches decouple the atmosphere and ocean using atmospheric correction procedures, which are performed in two steps. First, the aerosol reflectance, after the correction of Rayleigh scattering and surface reflectance, is estimated by comparing measurements with lookup tables (LUTs) in the red or near-infrared (NIR) channels, where the water-leaving radiance can be neglected due to the high absorption of waters at those bands. The LUTs contain precalculated radiation fields for sets of candidate aerosol modes, which are characterized by different optical properties and relative humidity values. Second, the best fitting aerosol modes are selected and extrapolated to shorter wavelengths to calculate the aerosol scattering and water-leaving radiance in those band regions (Gordon and Wang, 1994; Fukushima et al., 1998; Antoine and Morel, 1999; Gao et al., 2000; Wang, 2010). In addition, other efforts or approaches have been made to compensate the traditional atmospheric correction procedures under more challenging measurement conditions in the presence of non-null water-leaving radiance of turbid waters. Such methods use aerosol optical properties of nearby non-turbid areas or other spectral information, such as ultraviolet or shortwave infrared (SWIR) bands (Hu et al., 2000; Ruddick et al., 2000; Pan and Mao, 2001; Wang and Shi, 2007; He et al., 2012; Mao et al., 2013), as well as iteration techniques to determine the NIR $L_{\mathrm{w}}$ values derived from bio-optical models and $L_{\mathrm{w}}$ at visible bands based on convergence criterion (Siegel et al., 2000; Stumpf et al., 2003; Bailey et al., 2010). Furthermore, in consideration of the insufficiency of aerosol modes in the LUT approach, other research has expanded the LUTs to encompass more actual aerosol models derived from Aerosol Robotic Network (AERONET) observations (Ahmad et al., 2010) or combined with the aerosol scattering using the linear combination method (Frouin et al., 2006; Shi and Nakajima, 2017). In this respect, after the process of atmospheric correction, the water-leaving radiance, which only typically accounts for $\sim 10 \%$ of satellite-observed signal, is determined. To further reduce errors caused by the atmospheric correction algorithm and instrumental radiometric uncertainties, vicarious calibration is conducted to improve the accuracy of $L_{\mathrm{w}}$ by comparing satellite-observed radiance with simulations using ground-truth observation data (Gordon, 1998; Fougnie et al., 1999; Wang and Franz, 2000; Murakami et al., 2005; Yoshida et al., 2005; Franz et al., 2007).

However, many of these algorithms rely on the observation of only several spectral channels; the retrieved aerosol spectral properties are not always fully consistent with the measurements at other bands (Jeong and Li, 2005; Dubovik et al., 2011; Kahn et al., 2016), and the retrieved $L_{\mathrm{w}}$ values are sometimes negative due to the overestimation of aerosol scattering, particularly in short wavelengths (Fan et al., 2017). In the past decades, other feasible methods using a direct optimization-based inversion algorithm (Bricaud and Morel, 1987; Doerffer and Fischer, 1994; Zhao and Nakajima, 1997; Chomko and Gordon, 1998; Stamnes et al., 2003; Dubovik et al., 2008; Li et al., 2008; Kuchinke et al., 2009; Shi et al., 2016) or Bayesian methodology (Frouin and Pelletier, 2015) have been developed to complement prevailing atmospheric correction schemes. These retrieval approaches involve a direct inversion scheme that simultaneously determines aerosol, radiometric quantities or oceanic substances with minimal assumption, which have an advantage in dealing flexibly with the inversion problems in the absorption aerosol loading conditions and increasing the available measurement's information content. Most of these approaches adopt the radiative transfer (RT) model to enable simulated radiance to converge with observations by defining the appropriate retrieved parameters and estimation schemes or neural network method (Schroeder et al., 2007; Fan et al., 2017) to make full use of the satellite-observed data, as well as multiple geometry, pixel or polarization information (Dubovik et al., 2011; Hasekamp et al., 2011; Knobelspiesse et al., 2012; Xu et al., 2016).

To model the radiative transfer in the atmosphere and ocean system, simple methods use the Fresnel-Snell law to combine the two non-uniformly refracting layered media for a flat ocean surface. However, better modeling schemes are required with respect to wind speed for the rough ocean surface (Cox and Munk, 1954; Nakajima and Tanaka, 1983; Fischer and Grassl, 1984; Mobley, 1994; Fell and Fischer, 2001; Jin et al., 2006; Chowdhary et al., 2006; Ota et al., 2010; He et al., 2010; Zhai et al., 2010, 2017; Chami et al., 2015), particularly in the sunglint conditions. Sunglint is a major issue for the remote sensing of aerosols or ocean color. In sunglint-contaminated satellite ocean imagery, the received radiation can be so bright that there may be significant errors in the satellite retrieval of atmospheric and oceanic components, and sometimes obtaining relevant information is even impossible. This is related to the strong reflectance of the ocean surface, which is like a mirror and generates information that is more robust than that of atmospheric scatter- 
ing and water-leaving radiance. Therefore, satellite instruments, such as CZCS, SeaWiFS and POLDER, have a tilting capacity to avoid sunglint observation. However, for the MODIS and the Medium Resolution Imaging Spectrometer (MERIS) which have no glint tilting function, glint contamination might be more severe. Nevertheless, studies suggest that sunglint information can be valuable for many applications. For example, it can provide additional information content for the retrieval of aerosol optical properties and types including absorption aerosol (Kaufman et al., 2002; Ottaviani et al., 2013). In addition, the sunglint signal is useful in oil monitoring (Chust and Sagarminaga, 2007; Hu et al., 2009), investigation of below-surface conditions ( $\mathrm{Hu}$, 2011) and retrieval of wind speed over the ocean surface (Bréon and Henriot, 2006; Harmel and Chami, 2012). To correct sunglint contamination in the atmospheric correction process, several approaches have been introduced using the Cox-Munk sea surface model (Cox and Munk, 1954) to calculate direct solar reflectance from the wind speed prediction (Wang and Bailey, 2001) or the spectral matching method (Steinmetz et al., 2011).

Recent studies suggest that there are still some questionable results in coastal waters using those improved atmospheric correction schemes (Jamet et al., 2011; Goyens et al., 2013), due to the existence of high aerosol loading or more optically complex oceanic substances, such as sediment or colored, dissolved organic matter (CDOM), than that in open waters where only chlorophyll $a$ concentration (Chl) dominates, since the null water-leaving radiance assumption breaks down. Besides, even the slight sunglint signals may also introduce large uncertainties in the retrieval of aerosol optical thickness (AOT) and $L_{\mathrm{w}}$. In an effort to cover such problems, we introduce an iterative fitting scheme in this study, which is the simultaneous retrieval of AOT and water-leaving radiance from multispectral measurements in coastal waters. To minimize the uncertainties of spectral radiance from traditional atmospheric correction schemes in the decoupled atmosphere-ocean system, the forward radiation calculation is performed using a coupled radiative transfer model combined with a comprehensive bio-optical oceanic module. Then, a nonlinear optimization approximation approach constrained by a global three-dimensional spectral radiation-transport aerosol model (Takemura et al., 2000) is used to jointly estimate aerosol optical thickness (fine, sea spray and dust), wind speed and oceanic substances, which consist of Chl, sediment and CDOM, based on the multispectral observations. The spectral water-leaving radiance is correspondingly estimated through the developed bio-optical module followed by a full physical formulation for the calculation of transmission matrix of rough ocean surface simultaneously.

The objectives of this paper are (1) to calibrate the algorithm in the estimation of AOT and $L_{\mathrm{w}}$ based on vicarious calibration, (2) to validate the availability of the optimal estimation algorithm from in situ measurements us- ing Aerosol Robotic Network - Ocean Color (AERONETOC) products and (3) to estimate the inversion accuracy in the condition of sunglint measurements. The general structure of the bio-optical module and design of the retrieval algorithm are introduced in Sect. 2. The datasets used and the strict spatial-temporal match-up criteria are shown in Sect. 3. Then, we present retrieval results derived from the MODIS instrument after vicarious calibration and compare them with in situ products collected from eight AERONETOC sites distributed over different ocean regions, as well as the products from the MODIS standard atmospheric correction scheme. As an illustration, retrievals are conducted using all available satellite data covering both in- and out-ofsunglint observations. Finally, the conclusion and perspectives are provided in the last section.

\section{Procedure of the retrieval algorithm}

\subsection{Atmospheric module}

In this study, the forward RT simulation is performed by a vector coupled atmosphere-ocean model (Ota et al., 2010). The model employs the discrete ordinate and matrix operator method and was developed based on the Nakajima-Tanaka scheme (Nakajima and Tanaka, 1983, 1986, 1988). It has been proven to be highly accurate in simulating the radiation processes in the atmospheric system (Kokhanovsky et al., 2010). In this algorithm, six different atmospheric profiles, midlatitude summer/winter, sub-arctic summer/winter, tropical and US standard profiles are adopted based on the observation time and location. The atmosphere is divided into 15 layers with the top at $120 \mathrm{~km}$ above the surface. The gas absorption coefficient is calculated by a correlated $k$ distribution approach (Sekiguchi and Nakajima, 2008) where several main absorptive gases of water vapor, carbon dioxide, ozone, nitrous oxide, carbon monoxide, methane and oxygen are considered. The depolarization factor of atmospheric Rayleigh scattering is assumed as 0.0279. For the aerosol, a more realistic scattering multicomponent approach is adopted within the aerosol model, wherein the refractive index of each component of the aerosol particle is calculated considering hygroscopic growth (Shettle and Robert, 1979; Yan et al., 2002). It is assumed that the external mixture aerosol model consists of fine particles, sea spray particles and dust particles (which are defined as non-spherical particles), and that an internal mixture of water-soluble, dustlike and soot aerosols exists within the fine particles, from which the refractive index is calculated by the sum of each internal component contribution based on its volume fraction. The fine and sea spray particles are added from the surface to $2 \mathrm{~km}$ height, while dust particles are added from $4 \sim 8 \mathrm{~km}$ height, where the vertical distributions of fine and dust particles are homogeneous in contrast to those of sea spray particles with exponential decrease. For each exter- 
Table 1. Aerosol modes used in this study.

\begin{tabular}{llrrrr}
\hline Type & Components & Spherical & $\begin{array}{r}\text { Height } \\
(\mathrm{km})\end{array}$ & $\begin{array}{r}r_{m} \\
(\mu \mathrm{m})\end{array}$ & $s$ \\
\hline Fine & Water-soluble, dust-like and soot & Yes & $0 \sim 2$ & 0.175 & 2.240 \\
Sea spray & Sea salt & Yes & $0 \sim 2$ & 2.200 & 2.010 \\
Dust & Dust-like/Yellow sand* & No & $4 \sim 8$ & 4.000 & 3.000 \\
\hline
\end{tabular}

* The yellow sand mode (Nakajima et al., 1989) is only used in the retrieval of AOT at Ieodo_Station.

nal particle type, the size distribution is assumed to follow a log-normal distribution (Nakajima and Higurashi, 1997; Higurashi et al., 1999; Dubovik and King, 2000) as follows:

$\frac{\mathrm{d} V}{\mathrm{~d} \ln r}=C \exp \left[-\frac{1}{2}\left(\frac{\ln r-\ln r_{m}}{\ln s}\right)^{2}\right]$,

where $C$ denotes the particle volume concentration, $V$ is the aerosol volume density, $r_{m}$ is the mode radius, and $\ln s$ is the standard deviation (SD) of $\ln r$. The phase matrix of aerosols is calculated by Mie theory for spherical particles and Dubovik et al.'s (2002) method for non-spherical particles. In general, the aerosol modes are summarized in Table 1 .

\subsection{Bio-optical oceanic module}

The accuracy of the RT scheme in the ocean system is conducted based on a comparison to the standard underwater RT problem proposed by Mobley et al. (1993) (Shi et al., 2015). In this study, we implement a three-component bio-optical module developed by Shi et al. (2016) to model the inherent optical properties (IOPs) of oceanic substances. A brief overview of procedures is shown in Table 2. However, we do make some slight changes to the module in relation to the seawater absorption coefficient based on a calibration between retrieval and measurement. It assumes that the ocean is divided into four layers with infinite depth, where the vertical distributions of oceanic substances are homogeneous except that of Chl defined as Gaussian (Morel and Maritorena, 2001). The Raman scattering is temporarily neglected in the current model.

After the modeling of IOPs of oceanic substances, the reflection and transmission matrices for each oceanic layer are obtained through the discrete ordinate solution. Then, the adding theory is applied to determine the unknown integral constants and solve the inhomogeneous layer in the coupled atmosphere-ocean system (Ota et al., 2010). To connect the water-leaving radiance with the underwater light field, we develop a full physical technique to calculate $L_{\mathrm{w}}$ in the model as

$$
\begin{aligned}
\mathrm{L}_{\mathrm{w}} & \left(\lambda ; \mu, \phi ;[\mathrm{Chl}], S_{\mathrm{s}}, a_{y}(440)\right) \\
\quad & =\sum_{m=0}^{M-1} L_{\mathrm{w}}^{m}\left(\lambda ; \mu ;[\mathrm{Chl}], S_{\mathrm{s}}, a_{y}(440)\right) \frac{\cos m \phi}{\pi\left(1+\delta_{0 m}\right)},
\end{aligned}
$$

where $\lambda$ is the wavelength and $\delta_{0 m}$ denotes Kronecker's delta; $\mu$ and $\phi$ are the cosine of the viewing zenith angle and relative azimuth angle, respectively. [Chl], $S_{\mathrm{s}}$ and $a_{y}(440)$ are concentrations of Chl, sediment and CDOM, respectively. $L_{\mathrm{w}}^{m}$ is the $m$ th-order Fourier component of $L_{\mathrm{w}}$ as calculated by

$$
\begin{aligned}
& L_{\mathrm{w}}^{m}\left(\lambda ; \mu ;[\mathrm{Chl}], S_{\mathrm{s}}, a_{y}(440)\right)=\sum_{i=1}^{N_{\mathrm{s}}} L_{u}^{m} \\
& \cdot\left(\lambda ; \tau^{0-} ; \mu_{i} ;[\mathrm{Chl}], S_{\mathrm{s}}, a_{y}(440)\right) T^{m}\left(\lambda ; \mu, \mu_{i}\right), \\
& T^{m}\left(\lambda ; \mu, \mu_{i}\right)=\frac{1}{\mu_{i}} \int_{\mu_{i}-1 / 2}^{\mu_{i}+1 / 2} \mu^{\prime} \mathrm{d} \mu^{\prime} \int_{0}^{2 \pi} \\
& \quad T\left(\lambda ; \mu, \mu^{\prime} ; \phi\right) \cos m \phi \mathrm{d} \phi,
\end{aligned}
$$

where $L_{u}^{m}$ denotes the $m$ th-order Fourier component of upward radiance just below the ocean surface $\left(\tau^{0-}\right)$, which can be calculated by the adding method in the model; $\mu_{i}$ are the points for a discrete quadrature of $N_{\mathrm{s}}$ in the ocean system. $T\left(\lambda ; \mu, \mu^{\prime} ; \phi\right)$ is the diffuse transmission function of rough ocean surface related to the emergent and incident normal angles, $\mu$ and $\mu^{\prime}$, just above and below the ocean surface, respectively. $T\left(\lambda ; \mu, \mu^{\prime} ; \phi\right)$ can be derived from wind speed values based on the ocean surface mode of Nakajima and Tanaka (1983). To be consistent with the conventional ocean color products using normalized water-leaving radiance $\left(\mathrm{nL}_{\mathrm{w}}\right)$, which is approximately the water-leaving radiance in the absence of atmosphere, with the Sun at the zenith and the mean Earth-Sun distance (Gordon and Clark, 1981), $\mathrm{nL}_{\mathrm{w}}$ is computed as

$$
\begin{aligned}
& \mathrm{nL}_{\mathrm{w}}\left(\lambda ;[\mathrm{Chl}], S_{\mathrm{s}}, a_{y}(440)\right) \\
& \quad=\left(\frac{d_{0}}{d}\right)^{2} \frac{\mathrm{L}_{\mathrm{w}}\left\{\lambda ; \text { Nadir; }[\mathrm{Chl}], S_{\mathrm{s}}, a_{y}(440)\right\}}{E_{\mathrm{d}}^{0+}(\lambda)} F_{0}(\lambda),
\end{aligned}
$$

where $d_{0}$ is the Earth-Sun average distance where solar irradiance $F_{0}$ is reported; $d$ is the Earth-Sun distance when the measurement is conducted. $E_{\mathrm{d}}^{0+}$ is the downward irradiance just above the ocean surface.

\subsection{Optimization approach for retrieval}

In the nonlinear atmosphere and ocean system, the measurements vector $\boldsymbol{y}$, such as the observed radiance or reflectance 
Table 2. Bio-optical ocean module used in the RT model.

\begin{tabular}{|c|c|c|c|}
\hline Component & Parameters & Formula $^{\mathrm{a}}$ & References \\
\hline \multirow[t]{5}{*}{ Seawater } & $\begin{array}{l}\text { Real part of } \\
\text { refractive index }\end{array}$ & $\begin{array}{l}n_{r}(T, S, \lambda)=n_{\mathrm{a}} \times\left[n_{0}+\left(n_{1}+n_{2} T+n_{3} T^{2}\right) S\right. \\
\left.+n_{4} T^{2}+\left(n_{5}+n_{6} S+n_{7} T\right) / \lambda+n_{8} / \lambda^{2}+n_{9} / \lambda^{3}\right]\end{array}$ & $\begin{array}{l}\text { Hale and Querry (1973) } \\
\text { Quan and Fry (1995) } \\
\text { Huibers (1997) } \\
\text { Zhang and Hu (2009) }\end{array}$ \\
\hline & $\begin{array}{l}\text { Imaginary part of } \\
\text { refractive index }\end{array}$ & Cubic spline fitting & $\begin{array}{l}\text { Hale and Querry (1973) } \\
\text { Smith and Baker (1981) } \\
\text { Kou et al. (1993) } \\
\text { Pope and Fry (1997) } \\
\end{array}$ \\
\hline & $\begin{array}{l}\text { Absorption } \\
\text { coefficient }\end{array}$ & $\begin{array}{l}a_{w}(T, S, \lambda)=a_{w}\left(T_{0}, S_{0}, \lambda\right)+\left(T-T_{0}\right) \psi_{T}(\lambda) \\
+\left(S-S_{0}\right) \psi_{S}(\lambda)\end{array}$ & Röttgers et al. (2010) \\
\hline & $\begin{array}{l}\text { Scattering } \\
\text { coefficient }\end{array}$ & $b_{w}(T, S, \lambda)=\frac{8 \pi}{3} \beta_{w}\left(90^{\circ}, T, S, \lambda\right) \frac{2+\delta_{w}}{1+\delta_{w}}$ & $\begin{array}{l}\text { Zhang et al. (2009) } \\
\text { Zhang and } \mathrm{Hu}(2009)\end{array}$ \\
\hline & $\begin{array}{l}\text { Phase } \\
\text { function }\end{array}$ & $\beta_{w}(\Theta, T, S, \lambda)=\beta_{w}\left(90^{\circ}, T, S, \lambda\right)\left(1+\frac{1-\delta}{1+\delta} \cos ^{2} \Theta\right)$ & Morel (1974) \\
\hline \multirow[t]{3}{*}{ Chl } & $\begin{array}{l}\text { Absorption } \\
\text { coefficient }\end{array}$ & $a_{\mathrm{ph}}(\lambda)=A(\lambda)[\mathrm{Chl}]^{1-B(\lambda)}$ & $\begin{array}{l}\text { Bricaud et al. (1995) } \\
\text { Morrison and Nelson (2004) } \\
\text { Mobley (2014) }\end{array}$ \\
\hline & $\begin{array}{l}\text { Scattering } \\
\text { coefficient }\end{array}$ & $b_{\mathrm{ph}}(\lambda)=0.347[\mathrm{Chl}]^{0.766}[\lambda / 660]^{v([\mathrm{Chl}])}$ & $\begin{array}{l}\text { Morel and Maritorena (2001) } \\
\text { Huot et al. (2008) }\end{array}$ \\
\hline & $\begin{array}{l}\text { Phase } \\
\text { function }^{b}\end{array}$ & $\begin{array}{l}P_{\mathrm{ph}}(\Theta)=\frac{1}{4 \pi(1-\delta)^{2} \delta^{v}}\left\{v(1-\delta)-\left(1-\delta^{v}\right)+\left[\delta\left(1-\delta^{v}\right)\right.\right. \\
\left.\left.-v(1-\delta) \sin ^{-2}(\Theta / 2)\right]\right\}+\frac{1-\delta_{180}^{v}}{16 \pi\left(\delta_{180}-1\right) \delta_{180}^{v}}\left(3 \cos ^{2}(\Theta)-1\right) \\
v=(3-\mu) / 2, \delta=4 /[3(n-1)] \sin ^{2}(\Theta / 2)\end{array}$ & Fournier and Forand (1994) \\
\hline \multirow[t]{2}{*}{ Sediment } & $\begin{array}{l}\text { Scattering } \\
\text { coefficient }\end{array}$ & $b_{\text {sed }}(\lambda)=b_{\mathrm{S}}(550)(\lambda / 550)^{n_{\mathrm{s}}} S_{\mathrm{s}}$ & Tassan (1994) \\
\hline & $\begin{array}{l}\text { Phase } \\
\text { function }^{b}\end{array}$ & $\begin{array}{l}P_{\text {sed }}(\Theta)=\frac{1}{4 \pi(1-\delta)^{2} \delta^{v}}\left\{v(1-\delta)-\left(1-\delta^{v}\right)+\left[\delta\left(1-\delta^{v}\right)\right.\right. \\
\left.\left.-v(1-\delta) \sin ^{-2}(\Theta / 2)\right]\right\}+\frac{1-\delta_{180}^{v}}{16 \pi\left(\delta_{180}-1\right) \delta_{180}^{v}}\left(3 \cos ^{2}(\Theta)-1\right) \\
v=(3-\mu) / 2, \delta=4 /[3(n-1)] \sin ^{2}(\Theta / 2)\end{array}$ & Fournier and Forand (1994) \\
\hline CDOM & $\begin{array}{l}\text { Absorption } \\
\text { coefficient }\end{array}$ & $a_{y}(\lambda)=a_{y}(440) \exp (-0.014(\lambda-440))$ & Bricaud et al. (1981) \\
\hline
\end{tabular}

a $T(0-30)$ is temperature in ${ }^{\circ} \mathrm{C} ; \mathrm{S}(0-40)$ is salinity in practical salinity units (PSUs); $\psi_{T}(\lambda)$ and $\psi_{S}(\lambda)$ are the temperature and salinity correction coefficients for water absorption; $\beta_{w}\left(90^{\circ}\right)$ is the volume scattering function at $90^{\circ} ; \delta_{w}$ is the depolarization factor defined as 0.039 by default (Zhang et al., 2009). $S_{\mathrm{S}}$ and $a_{y}(440)$ are the concentration of sediment and absorption coefficient of CDOM at $440 \mathrm{~nm}$. The absorption effect of sediment is neglect. Besides, CDOM is assumed as a pure absorber. $\mathrm{b}$ The phase function is an analytical approximation form of the scattering angular distribution of an ensemble of particles. It has a hyperbolic size distribution based on the exact Mie theory and is calculated using the real part of particles' refractive index, $n$ and slope parameter, $\mu$. For chlorophyll, $n$ and $\mu$ are determined as 1.068 and 3.38 to derive the backscattering fraction is 0.0065 , as used by Li et al. (2008). For sediment, $n$ and $\mu$ are fixed at 1.200 and 3.275 so that the backscattering fraction corresponds to 0.015 , as used by Tassan (1994).

in each channel, can be simplified by an expression of forward radiative transfer model $F(\boldsymbol{x}, \boldsymbol{b})$ with error $\boldsymbol{\varepsilon}$, which consists of measurement error and model error.

$\boldsymbol{y}=F(\boldsymbol{x}, \boldsymbol{b})+\boldsymbol{\varepsilon}$,

where $\boldsymbol{x}$ is the state vector for a set of parameters being retrieved, and $\boldsymbol{b}$ comprises the quantities that influence the observation but are not to be retrieved. The inversion problem is to determine $\boldsymbol{x}$ from the observations $\boldsymbol{y}$. Such an equation can be solved by Bayesian theory based on the assump- tion that the probability distribution function of measurement and the state vector are Gaussian distributions (Rodgers, 2000). Then, the maximum a posteriori optimization approach is adopted to minimize the cost function under the condition that a priori information is constrained. The optimal solution of retrieved parameters is determined in an iterative way through the Newton iteration method optimized by the Levenberg-Marquardt algorithm (Levenberg, 1944; Marquardt, 1963) to accelerate the convergence of the algorithm 
as

$$
\begin{gathered}
\boldsymbol{x}_{i+1}=\boldsymbol{x}_{i}+\left[\left(\mathbf{K}_{i}^{\mathrm{T}} \mathbf{S}_{\varepsilon}^{-1} \mathbf{K}_{i}+\left(1+\gamma_{i}\right) \mathbf{S}_{\mathrm{a}}^{-1}\right)\right]^{-1} \\
\cdot\left[\mathbf{K}_{i}^{\mathrm{T}} \mathbf{S}_{\varepsilon}^{-1}\left(\boldsymbol{y}-F\left(\boldsymbol{x}_{i}\right)\right)-\mathbf{S}_{\mathrm{a}}^{-1}\left(\boldsymbol{x}_{i}-\boldsymbol{x}_{\mathrm{a}}\right)\right],
\end{gathered}
$$

where $\boldsymbol{x}_{i}$ is the state vector to be retrieved at the $i$ th iteration; $\boldsymbol{x}_{\mathrm{a}}$ denotes the priori values of the state vector, $\mathbf{S}_{\varepsilon}$ is the measurement error covariance matrix, and $\mathbf{S}_{\mathrm{a}}$ is the variancecovariance matrix defined by a priori state values; $\mathbf{K}$ is the Jacobian matrix or weighting function, which is derived by the forward model to the state vector as $\mathbf{K}=\partial F(\boldsymbol{x}) / \partial \boldsymbol{x} . \gamma$ is a non-negative parameter chosen in each iteration to minimize the cost function using the method of Press (1994). Since the retrieved state vector is usually non-unique and also follows a Gaussian distribution with expected value $\hat{\boldsymbol{x}}$ and covariance $\hat{\mathbf{S}}$, the statistical uncertainties in retrieved parameters are given as

$\hat{\mathbf{S}}=\left(\mathbf{K}^{T} \mathbf{S}_{\varepsilon}^{-1} \mathbf{K}+\mathbf{S}_{\mathrm{a}}^{-1}\right)^{-1}$,

where the square roots of its diagonals are the $1 \sigma$ uncertainties of each retrieved parameter.

In this study, the state vector, $\boldsymbol{x}$, consisted of eight parameters needed to be retrieved: AOT of fine particles, AOT of sea spray, AOT of dust, volume soot fraction in fine particles, wind speed, [Chl], $S_{\mathrm{s}}$ and $a_{y}(440)$. The soot fraction in fine particles is assumed as the retrieval parameters to consider the inversion cases of absorptive aerosol loading. The spectral $\mathrm{nL}_{\mathrm{w}}$ values are calculated based on Eqs. (2)(4) simultaneously. In terms of the priori information in the retrieval, a global three-dimensional spectral radiationtransport aerosol model named SPRINTARS (Takemura et al., 2000) is used to generate the a priori and uncertainty conditions of AOT for each type. Besides, the annual average and variance values of Chl from MODIS Level 3 products in 2009 are adopted as the priori constrain for the determination of Chl. The a priori and uncertainty values of sediment and CDOM are defined as $1.0 \mathrm{~g} \mathrm{~m}^{-3}$ and $0.1 \mathrm{~m}^{-1}$, respectively. The algorithm corrects the satellite-received reflectance using Ozone Monitoring Instrument (OMI) data for ozone absorption and relative humidity, surface temperature, pressure and wind speed from the National Centers for Environmental Prediction (NCEP) reanalysis data. A global averaged value of 35.5 PSUs of oceanic salinity is used temporarily in the current algorithm. The general flowchart of the retrieval scheme is shown in Fig. 1.

\section{Data and statistical method}

\subsection{MODIS data}

MODIS/Aqua Level $1 \mathrm{~b}$ radiances and geometry information with $1 \mathrm{~km}$ spatial resolution obtained from the Collection 6 dataset derived from the MODIS land and atmosphere team

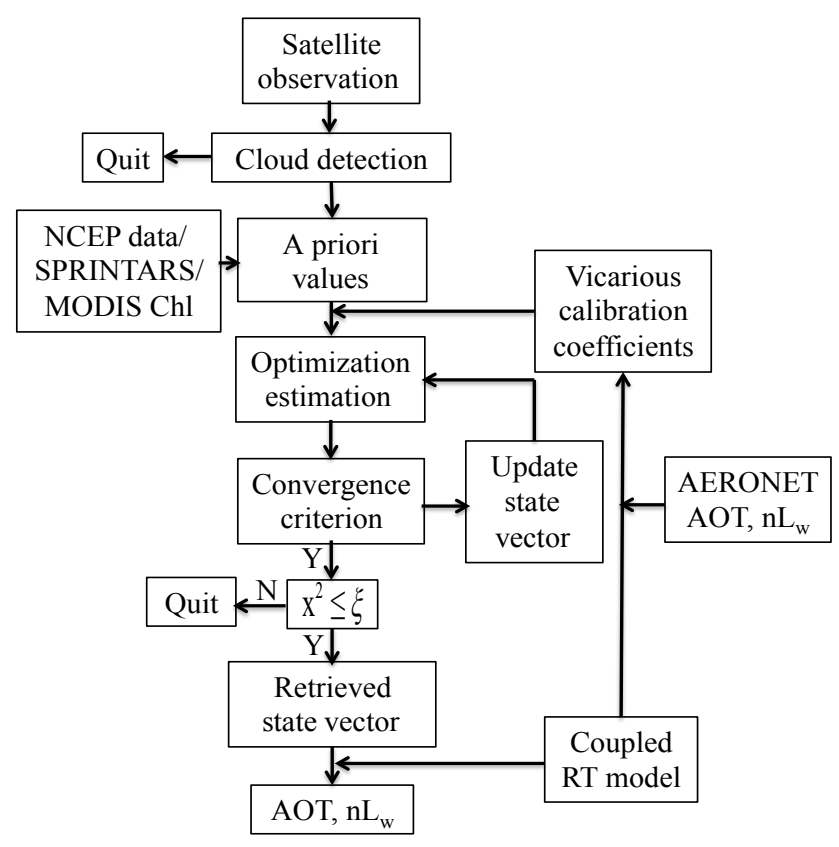

Figure 1. Flow chart of the retrieval algorithm.

are used in this study because of the highly accurate instrument calibration and wide observation bands used. Eight wavelength measurements within the nominal central wavelengths of 412, 442, 488, 554, 678, 747, 869 and $1640 \mathrm{~nm}$ are adopted in the joint inversion of aerosol and $\mathrm{nL}_{\mathrm{w}}$. Those wavelengths are selected so that the number of the measurement vectors is consistent with the number of unknown parameters. In addition, the selected spectral observations are sensitive to either variations in aerosols or oceanic substances.

\subsection{In situ data}

The AERONET-OC dataset is employed in this study to validate the accuracy of retrieved AOT and $\mathrm{nL}_{\mathrm{w}}$ using the simultaneous retrieval algorithm. AERONET is a globally distributed ground-based aerosol monitoring system used for validating aerosol optical properties (Holben et al., 1998). In 2006, a new component (AERONET-OC) was established and implemented to support long-term satellite ocean color investigations. It uses cross-site consistent and accurate measurements collected by modified Sun photometers installed on offshore fixed platforms (Zibordi et al., 2009). Both the atmospheric condition, such as aerosol and Rayleigh optical thickness, and the oceanic condition, such as normalized water-leaving radiance and chlorophyll $a$ concentration, are provided by AERONET-OC high-level products. In this study, level-2 data released after cloud-screening and from a quality-assured scheme of the NASA Goddard Space Flight Center are adopted for validation. The AERONET-OC in situ 


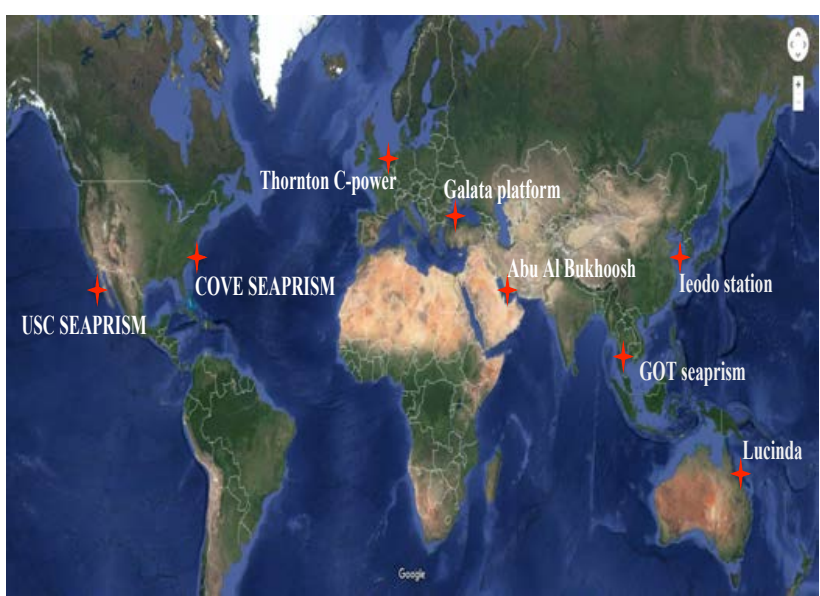

Figure 2. Locations of selected AERONET-OC stations (star symbols).

spectral values of AOT and $\mathrm{nL}_{\mathrm{w}}$ are interpolated using a cubic spline function to the satellite bands.

In situ data are selected and collected from eight AERONET-OC stations distributed in different ocean regions (as shown in Fig. 2) and then used to compare with satellite-derived results. The data are collected from four stations in the Pacific Ocean (Ieodo_Station, GOT_Seaprism, Lucinda and USC_SEAPRISM), two stations in the Atlantic Ocean (COVE_SEAPRISM and Thornton_C-power) and another two stations near the Sahara (Abu_Al_Bukhoosh and Galata_Platform, respectively). The period of the most available data used in this study is from 2010 to 2015 . The data are selected to enable consideration of the complexity and variation of local atmospheric and oceanic conditions, with the aim of reaching an objective and reasonable assessment of the satellite-retrieved data from the optimal estimation algorithm.

In addition, we also calculated the average and SD of AOT at $550 \mathrm{~nm}, \mathrm{Chl}, \mathrm{nL}_{\mathrm{w}}$ at $412,442,488$ and $554 \mathrm{~nm}$ (listed in Table 3) from all the observation values. It is demonstrated that there are distinct distributions for AOT and Chl within different ocean regions; high AOT loading can be seen at Ieodo_Station, GOT_Seaprism and Abu_Al_Bukhoosh, and high values of $\mathrm{Chl}$ are seen at Ieodo_Station, Thornton_Cpower and COVE_SEAPRISM.

\subsection{Comparison between satellite and in situ data}

In order to have a better comparison between satelliteretrieved results and in situ values, several criteria are adopted to extract the available data in this study: (1) more than 9 pixels can be analyzed successfully in $5 \times 5$ pixel windows around each AERONET-OC site; (2) the time difference between AERONET observations and the satellite overpass is less than $1 \mathrm{~h}$; (3) cloudy scenes are determined when the reflectance at $488 \mathrm{~nm}$ is greater than 0.4 , or the $\mathrm{SD}$ of satellite reflectance of $550 \mathrm{~nm}$ in $3 \times 3$ pixels is greater than 0.0025 (Remer et al., 2005); (4) the sunglint is assumed when the reflected Sun angle lies between 0 and $36^{\circ}$ (Ackerman et al., 1998); (5) the retrieved or in situ chlorophyll $a$ concentrations over $10 \mathrm{mg} \mathrm{m}^{-3}$ are excluded. By adopting strict spatial-temporal match-up criteria, 123 datasets are achieved, consisting of 105 cases where observations covered non-glint and 18 cases where observations covered glint.

Several statistical parameters are used in the evaluation, such as root mean square error (RMSE), average percentage difference (APD) and mean percentage bias, which are calculated as follows:

$$
\begin{aligned}
& \mathrm{RMSE}=\sqrt{\frac{\sum_{i=1}^{N}\left(y_{i}-x_{i}\right)^{2}}{N} ;} \\
& \mathrm{APD}=\frac{1}{N} \sum_{i=1}^{N}\left|\frac{y_{i}-x_{i}}{x_{i}}\right| \cdot 100 \% ; \\
& \mathrm{Bias}=\frac{1}{N} \sum_{i=1}^{N} \frac{y_{i}-x_{i}}{x_{i}} \cdot 100 \%,
\end{aligned}
$$

where $x_{i}$ is AERONET-OC results, $y_{i}$ is satellite-retrieved values, and $N$ is the number of match-up datasets.

\section{Results and discussions}

\subsection{Vicarious calibration}

The vicarious calibration is indispensable to have a better estimation of $\mathrm{nL}_{\mathrm{w}}$ since the desired uncertainties on $\mathrm{nL}_{\mathrm{w}}$ cannot be achieved through instrument calibration and characterizations alone (Gordon, 1998) due to the low proportion of $L_{\mathrm{w}}$ on the satellite-observed radiance. To derive vicarious calibration coefficients, which force the satellite radiance to agree with the simulated radiance, the ground-observed $\mathrm{nL}_{\mathrm{w}}$ as well as AOT values are used in the forward radiative transfer model. The effects of gas absorption, surface pressure, aerosols' wet growth process and polarization are all considered. However, we ignore the influence of whitecaps by limiting data with low surface wind speed.

In this study, the dataset of AOT at $550 \mathrm{~nm}$ and spectral $\mathrm{nL}_{\mathrm{w}}$ from one of AERONET-OC sites, i.e., Acqua Alta Oceanographic Tower (AAOT, also indicated as "Venise"), located in the northern Adriatic Sea at approximately 8 nautical miles from the main land, is adopted for the vicarious calibration. The site is selected since it provides an almost uninterrupted series of data with low uncertainties of $\mathrm{nL}_{\mathrm{w}}$ (Zibordi et al., 2015) in visible and near-infrared bands, and has also been successfully used by Mélin and Zibordi (2010) in the determination of calibration coefficients used in their algorithm. To have a set of quality-proven satellite and in situ measurement data, several criteria are adopted to select data. Generally, the match-up process is similar to those used 
Table 3. Mean values and the SD of in situ AOT at $550 \mathrm{~nm}, \mathrm{Chl}\left(\mathrm{mg} \mathrm{m}^{-3}\right)$ and $\mathrm{nL}_{\mathrm{W}}\left(\mathrm{mw} \mathrm{sr}^{-1} \mathrm{~cm}^{-2} \mu \mathrm{m}^{-1}\right)$ at selected stations.

\begin{tabular}{lrrrrrr}
\hline Station & AOT & [Chl] & nLw $(412 \mathrm{~nm})$ & $\mathrm{nLw}(442 \mathrm{~nm})$ & $\mathrm{nLw}(488 \mathrm{~nm})$ & $\mathrm{nLw}(554 \mathrm{~nm})$ \\
\hline Ieodo_Station & $0.250 \pm 0.191$ & $2.070 \pm 0.443$ & $1.502 \pm 0.351$ & $2.075 \pm 0.469$ & $2.852 \pm 0.580$ & $2.827 \pm 0.684$ \\
GOT_Seaprism & $0.248 \pm 0.118$ & $0.301 \pm 0.149$ & $0.870 \pm 0.278$ & $0.873 \pm 0.211$ & $0.847 \pm 0.145$ & $0.329 \pm 0.077$ \\
Lucinda & $0.075 \pm 0.035$ & $2.049 \pm 0.892$ & $0.776 \pm 0.403$ & $1.084 \pm 0.542$ & $1.435 \pm 0.695$ & $1.303 \pm 0.706$ \\
Abu_Al_Bukhoosh & $0.271 \pm 0.170$ & $0.890 \pm 0.397$ & $0.475 \pm 0.207$ & $0.602 \pm 0.262$ & $0.801 \pm 0.348$ & $0.548 \pm 0.318$ \\
Galata_Platform & $0.147 \pm 0.089$ & $1.512 \pm 2.466$ & $0.364 \pm 0.162$ & $0.535 \pm 0.241$ & $0.833 \pm 0.371$ & $0.846 \pm 0.352$ \\
Thornton_C-power & $0.125 \pm 0.092$ & $5.057 \pm 4.407$ & $0.418 \pm 0.186$ & $0.591 \pm 0.284$ & $0.934 \pm 0.464$ & $1.181 \pm 0.503$ \\
COVE_SEAPRISM & $0.087 \pm 0.062$ & $2.602 \pm 0.975$ & $0.428 \pm 0.241$ & $0.624 \pm 0.300$ & $0.977 \pm 0.426$ & $1.057 \pm 0.485$ \\
USC_SEAPRISM & $0.090 \pm 0.051$ & $0.505 \pm 0.564$ & $0.731 \pm 0.208$ & $0.742 \pm 0.179$ & $0.740 \pm 0.133$ & $0.339 \pm 0.088$ \\
\hline
\end{tabular}

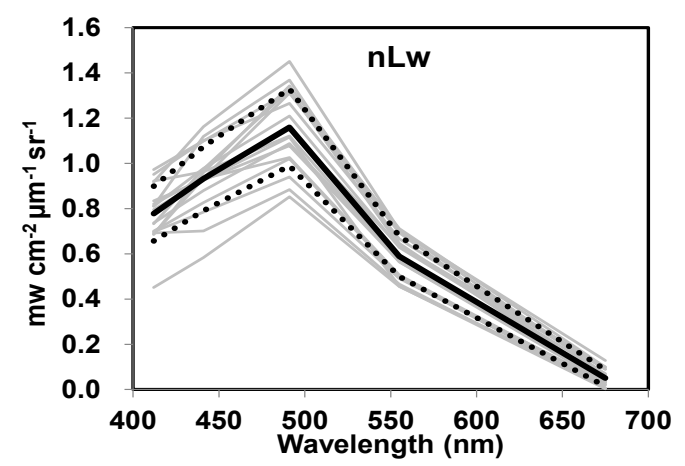

Figure 3. Spectra of AAOT $\mathrm{nL}_{\mathrm{w}}$ used for the calculation of vicarious calibration coefficients in this study. The gray lines represent the individual spectra; the black line shows the average spectrum; the dotted lines denote the average spectrum $\pm 1 \mathrm{SD}$.

for SeaWiFS from the study of Franz et al. (2007). (1) The chlorophyll $a$ concentration is lower than $0.2 \mathrm{mg} \mathrm{m}^{-3}$; (2) the aerosol optical thickness at $865 \mathrm{~nm}$ is lower than 0.15; (3) the satellite zenith angle and solar zenith angle are lower than 56 and $70^{\circ}$, respectively; (4) the reflected solar angle is larger than $36^{\circ}$ to exclude the sunglint conditions; (5) the wind speed at $10 \mathrm{~m}$ just above the ocean surface is lower than $7 \mathrm{~m} \mathrm{~s}^{-1}$. Due to the extensive quality screening process, 18 available data are selected for the vicarious calibration. It is studied that the derived coefficients show no significant temporal or geometric dependencies, and the mean values can be stabilized after approximate 20 high-quality calibration samples (Franz et al., 2007). The ensembles of $\mathrm{nL}_{\mathrm{w}}$ for each case are shown in Fig. 3, the average values of $\mathrm{nL}_{\mathrm{w}}$ are denoted by the black solid line.

We simulate radiance at the top of atmosphere using the above input data. Figure 4 demonstrates the averaged ratio of the simulated radiance using ground-truth data for the satellite-observed radiance in the band range from 400 to $800 \mathrm{~nm}$. It is demonstrated that the simulated radiance generally compares well with the satellite observation, with the ratio near 1 at $412 \mathrm{~nm}$. In the interval of $450-750 \mathrm{~nm}$, the coefficients are slightly lower than 1 , which indicates the simulated atmospheric contribution tends to be underestimated

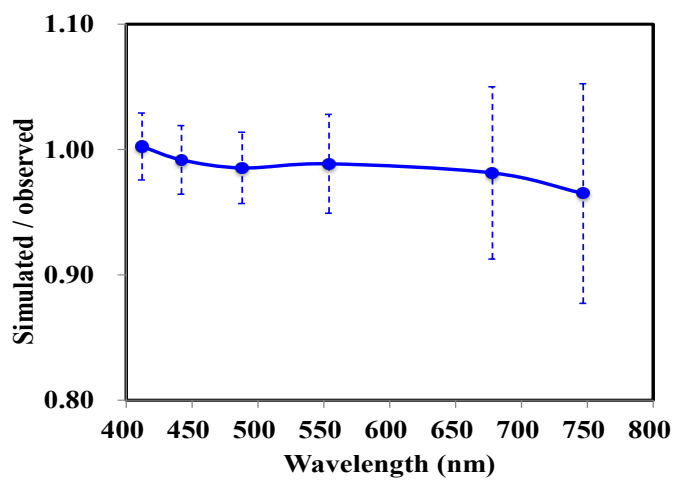

Figure 4. Averaged vicarious calibration coefficient for each channel.

in comparison with the satellite measurements. Moreover, larger variability is shown at longer wavelength.

\subsection{Using satellite measurements out of sunglint}

Based on the obtained vicarious coefficients, retrievals are firstly performed for eight in situ sites (shown in Fig. 2) to assess the accuracy of the algorithm using the satellite measurements out of sunglint. Figure 5 shows results of the comparison between simultaneously retrieved satellite AOT at $550 \mathrm{~nm}$ and $\mathrm{nL}_{\mathrm{w}}$ in $412,443,488$ and $554 \mathrm{~nm}$, with AERONET observation values. Here, AOT refers to the total aerosol optical thickness, which is the sum of the optical thickness of fine, sea spray and dust particles, and only the $\mathrm{nL}_{\mathrm{w}}$ values in shorter wavelengths are demonstrated in this study due to their more obvious sensitivity to the variation of $\mathrm{Chl}$ and more accurate measurements from AERONET-OC. It is noted that uncertainties for the AERONET-OC in situ $\mathrm{nL}_{\mathrm{w}}$ data are estimated at less than $5 \%$ in the $412-551 \mathrm{~nm}$ spectral range and at approximately $8 \%$ at $667 \mathrm{~nm}$ (Zibordi et al., 2009). At Ieodo_Station, the retrieved AOT and $\mathrm{nL}_{\mathrm{w}}$ are significantly consistent with the observation results shown in Fig. 5a. High aerosol loading and water reflectance conditions are demonstrated due to the transportation from inland pollutants as a result of the increase of oceanic substances or primary productivity 

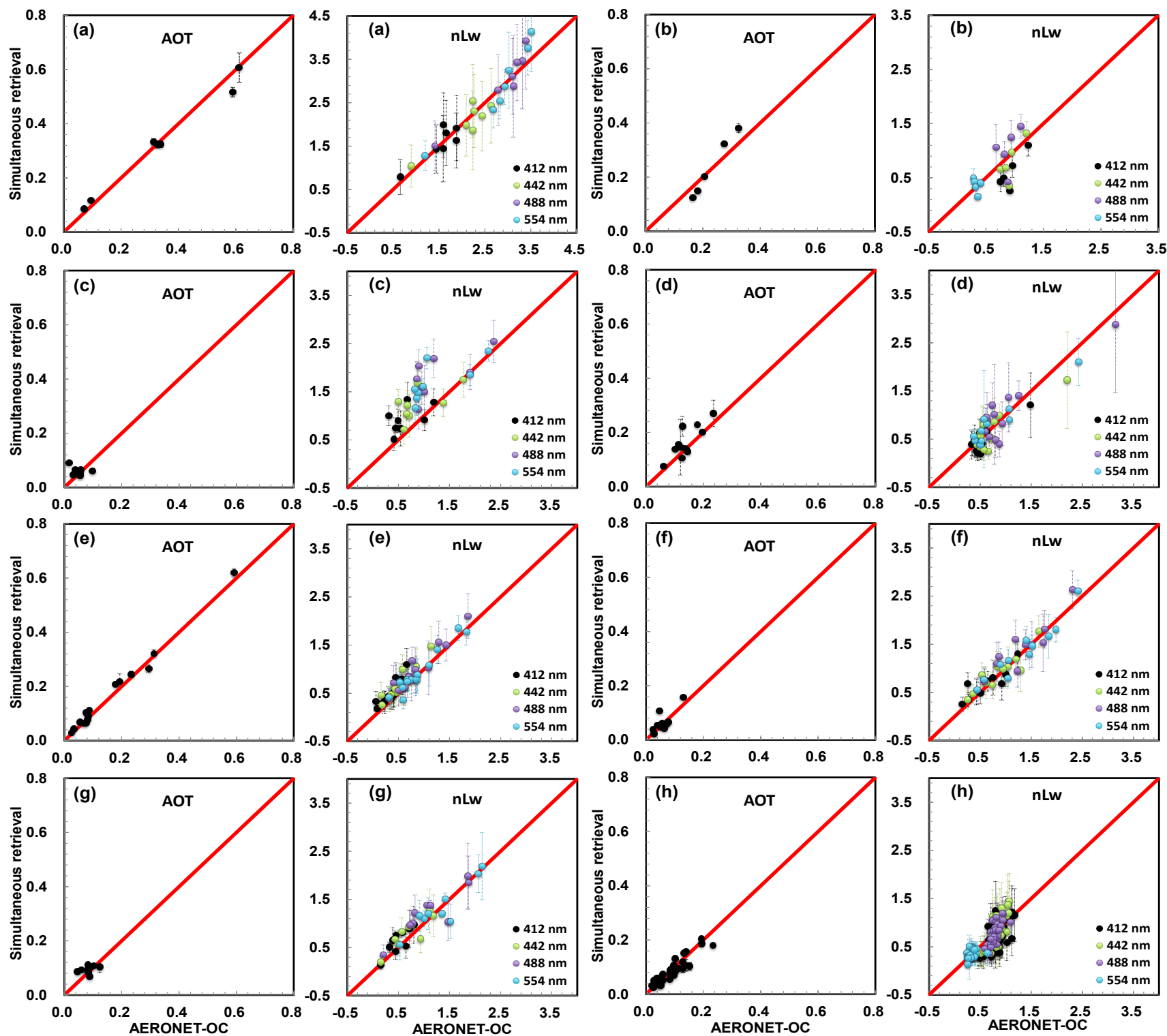

Figure 5. Comparison of simultaneously retrieved satellite AOT at $550 \mathrm{~nm}$ and $\mathrm{nL}_{\mathrm{w}}\left(\mathrm{mw} \mathrm{sr}^{-1} \mathrm{~cm}^{-2} \mu \mathrm{m}^{-1}\right)$ with AERONET-OC observations. The red line represents the $1: 1$ line. (a) Ieodo_Station; (b) GOT_Seaprism; (c) Lucinda; (d) Abu_Al_Bukhoosh; (e) Galata_Platform; (f) COVE_SEAPRISM; (g) Thornton_C-power; (h) USC_SEAPRISM.

(Tan et al., 2011; Huang et al., 2014). The retrieved Chl and sediment concentrations are mostly higher than those of other sites with averaged $\mathrm{Chl}$ and $S_{\mathrm{s}}$ up to 2.16 and $1.75 \mathrm{~g} \mathrm{~m}^{-3}$ in this study, since the location of this site is typically viewed as high turbid waters. In the GOT_Seaprism, the retrieved AOTs compare well with the AERONET-reported values; nevertheless, several inconsistent cases of $\mathrm{nL}_{\mathrm{w}}$ are shown in Fig. 5b: specifically, the derived $\mathrm{nL}_{\mathrm{w}}$ at $488 \mathrm{~nm}$ is generally overestimated. For the retrieval results at the Lucinda site (Fig. 5c) located in the Southern Hemisphere, low aerosol loading occurs in this station; however, the estimated $\mathrm{nL}_{\mathrm{w}}$ is overestimated in several cases, where the gen- eral variability patterns are significantly similar to those of MODIS standard OC products (not shown) as well as those that occurred in Abu_Al_Bukhoosh (Fig. 5d). In regards to the derived AOT in Galata_Platform and Abu_Al_Bukhoosh near the Sahara, the simultaneous retrieval algorithm has a good performance both in low and large aerosol concentration conditions, particularly for the Abu_Al_Bukhoosh site, where obvious higher AOTs of dust particles than those of other sites are derived with a good discrimination between sea spray and dust for the coarse aerosols in this study. In addition, the retrieved $\mathrm{nL}_{\mathrm{w}}$ are generally consistent with the observations with estimated Chl of $1.55 \mathrm{mg} \mathrm{m}^{-3}$ 

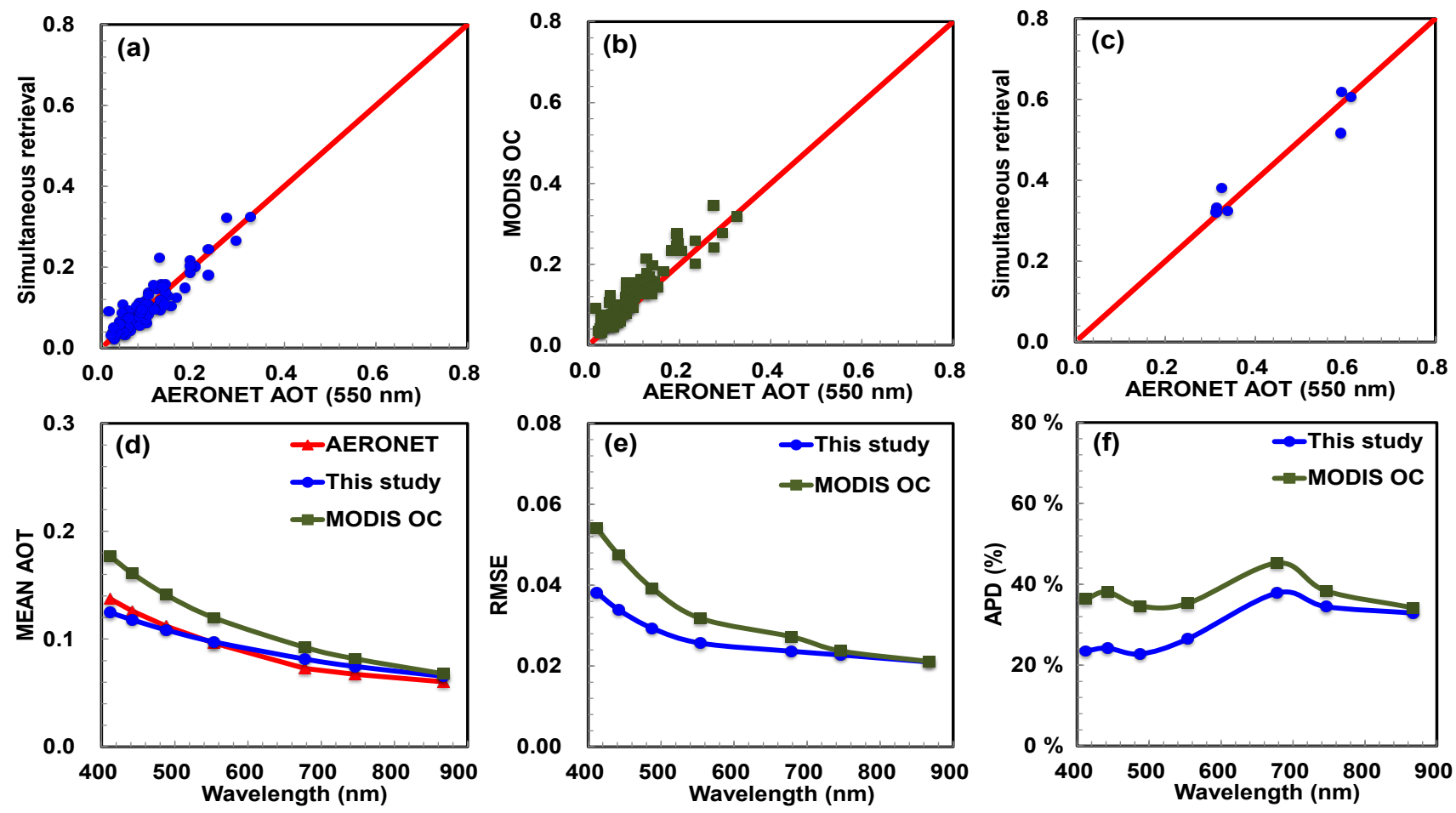

Figure 6. Comparison of jointly retrieved AOT at $550 \mathrm{~nm}$ from the simultaneous retrieval algorithm (a) and MODIS OC products (b) using satellite measurements out of sunglint with AERONET-OC in situ products. Comparison of retrieved AOT at $550 \mathrm{~nm}$ in high aerosol loading conditions from the current algorithm with AERONET-OC observation (c). Statistical mean AOT values (d), RMSE (e) and APD (f) results retrieved by these two approaches compared with AERONET-OC products at 412, 442, 488, 554, 670, 746 and $867 \mathrm{~nm}$.

on average in Galata_Platform (Fig. 5e), which is similar to the AERONET-reported value of $1.51 \mathrm{mg} \mathrm{m}^{-3}$. In the Atlantic Ocean, two AERONET sites, COVE_SEAPRISM and Thornton_C-power, are selected for the validation of the retrieval algorithm, and are located in the west and east coastal regions, respectively. Similar retrieval patterns are shown in Fig. $5 \mathrm{f}$ and $\mathrm{g}$. It is demonstrated that both the AOT and $\mathrm{nL}_{\mathrm{w}}$ can be well determined in this study with low aerosol concentration and inconspicuous changing pattern. Nevertheless, the retrieved $\mathrm{nL}_{\mathrm{w}}$ values have larger amplitudes of temporal variations that maybe imply the constantly changing of oceanic environment. At the USC_SEAPRISM site located on the west coast of United States, retrieved AOTs are very consistent with the AERONET-reported values, with correlation coefficient and RMSE of 0.9242 and 0.0202 , respectively; however, relatively slight temporal variations of $\mathrm{nL}_{\mathrm{w}}$ are shown at this site (Fig. 5h), which are obviously different from those of COVE_SEAPRISM (Fig. 5f) in east coastal regions.

Summaries of retrieved AOT at $550 \mathrm{~nm}$, which can be jointly derived from the current and MODIS standard atmospheric correction (AC) algorithms, vs. AERONET-OC observations are shown in the scatter plots in Fig. 6a and b, with the number of match-up pairs being 95 . Results demonstrate that both algorithms have an accurate estimation of
AOT in comparison to in situ measurements. However, the current algorithm shows a more accurate retrieval of AOT than the MODIS standard AC algorithm in which AOTs are a little overestimated. In addition, more cases can be determined in this study, particularly in the conditions of high aerosol loading demonstrated in Fig. 6c, in which most of those occur at the Ieodo_Station and Galata_Platform sites (shown in Fig. 5a and e). Furthermore, a comparison with AERONET-OC data demonstrates a better estimation of AOT for the current algorithm at other bands. Specifically, the mean AOTs derived by these two approaches are plotted in Fig. 6d. A greater consistency between measurements and estimation from the current algorithm is identified, while the mean AOTs retrieved by the standard AC scheme are generally overestimated, particularly at $412 \mathrm{~nm}$, since the retrieved $\mathrm{nL}_{\mathrm{w}}$ are sometimes negative. Such overestimation of AOT values from the standard $\mathrm{AC}$ algorithm was also reported by Goyens et al. (2013) and Fan et al. (2017) based on more data intercomparison. On the other hand, the simultaneous scheme decreases the RMSE of retrieved AOT by less than 0.04 and reduces APD values by almost up to $10 \%$ compared with those derived from the standard AC algorithm in the visible bands on average (shown in Fig. 6e and f). This is because all the spectral information can be used in the current algorithm to increase the information content and constraint 
in the inversion of AOT instead of conventional atmospheric correction schemes only using longer wavelengths, such as NIR or NIR/SWIR bands, and then extrapolate to shorter wavelengths. Moreover, the aerosol modes used in those two algorithms are different and may also influence the retrieval accuracy of AOT, from which the current scheme adopts a three-component external mixture mode with internal mixture in each type in the consideration of soot particles viewed as absorptive aerosol, while the MODIS standard AC algorithm uses the two-component model of Ahmad et al. (2010) based on data collected mainly in the open ocean. On the contrary, the retrieved AOTs from these two algorithms are significantly similar in the NIR bands, with the differences of RMSE and APD of 0.001 and $1.31 \%$ at $867 \mathrm{~nm}$, respectively, even though the visible spectral information is also used in this study, which also implied that the observation data in the NIR channels play a major role in the inversion of AOT, particularly AOT at NIR bands, while the simultaneous retrieval algorithm using multispectral measurements is more effective to derive AOT at visible bands.

Figure 7 shows comparisons of jointly retrieved $\mathrm{nL}_{\mathrm{w}}$ at 412, 442, 488 and $554 \mathrm{~nm}$ from the simultaneous retrieval algorithm and MODIS standard AC algorithm with AERONET-OC observations. Results indicate that atmospheric overcorrection can be avoided in order to have a better estimation of $\mathrm{nL}_{\mathrm{w}}$ at 412 and $442 \mathrm{~nm}$ using the simultaneous retrieval algorithm (shown in Fig. 7a), where several $\mathrm{nL}_{\mathrm{w}}$ values derived from the standard atmospheric correction scheme are negative (shown in Fig. 7b), which may be caused by the overestimation of AOT in those bands, just as Fig. 6d shows, or inappropriate estimation of Angström exponent. Particularly for the retrieval of $\mathrm{nL}_{\mathrm{w}}$ at $412 \mathrm{~nm}$, the simultaneous algorithm can reduce APD by up to $15 \%$ with a significant improvement compared with the standard AC scheme shown in Fig. 7d. However, the MODIS standard algorithm has a better estimation of $\mathrm{nL}_{\mathrm{w}}$ at $488 \mathrm{~nm}$ than those from the simultaneous retrieval approach with smaller values of RMSE and APD (Fig. 7c and d), even though more accurate retrieval of AOT at $488 \mathrm{~nm}$ using the current scheme is identified (shown in Fig. 6d-f). Possible reasons may arise from the deficient modeling of IOPs of oceanic substances in the ocean module of the RT model as small variations of IOPs might introduce large errors of $\mathrm{nL}_{\mathrm{w}}$ retrieval at blue bands just as Fig. 3 demonstrated; besides, the slight underestimation of AOT at $488 \mathrm{~nm}$ (shown in Fig. 6d) may also render the overestimation of $\mathrm{nL}_{\mathrm{w}}$ correspondingly. To develop empirical bio-optical schemes for the retrieval of $\mathrm{Chl}$, band ratios of the normalized water-leaving radiances are often used (O'Reilly et al., 1998). Figure 7e presents the comparison of ratios of $\mathrm{nL}_{\mathrm{w}}(442) / \mathrm{nL}_{\mathrm{W}}(554)$ and $\mathrm{nL}_{\mathrm{W}}(488) / \mathrm{nL}_{\mathrm{W}}$ (554) obtained from the two approaches with AERONET-OC observation values. Results demonstrate that the simultaneous retrieval algorithm obtains better inversion of $\mathrm{nL}_{\mathrm{W}}(442) / \mathrm{nL}_{\mathrm{W}}$ (554) and $\mathrm{nL}_{\mathrm{W}}(488) / \mathrm{nL}_{\mathrm{w}}$ (554), with RMSEs of 0.392 and 0.276 , respectively, and APDs of 16.30 and $11.34 \%$, respectively. In contrast, values from the MODIS standard AC algorithm are less consistent with AERONET-OC products, with RMSEs of 0.491 and 0.379 , respectively, and APDs of 24.50 and $12.94 \%$, respectively, even though there are not significant differences between RMSEs and APDs for the individual values of $\mathrm{nL}_{\mathrm{w}}$ at 442 and $554 \mathrm{~nm}$ shown in Fig. 7c and d. As a result, the estimated Chl from the current algorithm based on the OC4V4 scheme (without $\mathrm{nL}_{\mathrm{w}}$ at $510 \mathrm{~nm}$ in this study) (O'Reilly et al., 1998) is more consistent with the AERONET Chl products (Fig. 7f), with RMSE and APD of $0.571 \mathrm{mg} \mathrm{m}^{-3}$ and $36.35 \%$, in comparison to those from the MODIS standard AC approach of $0.849 \mathrm{mg} \mathrm{m}^{-3}$ and $41.27 \%$, respectively. It may be caused by the different methods adopted in these two algorithms for the determination of $L_{\mathrm{w}}$, where the current scheme calculates $L_{\mathrm{w}}$ mostly based on underwater conditions from Eq. (3), while $L_{\mathrm{w}}$ values derived by the MODIS operational scheme are obtained from the residual values of satellite radiance after atmospheric correction.

The algorithm is then applied to the selected image obtained around the East China Sea in October 2011. Spatial distributions of the simultaneous retrieval of total AOT at $550 \mathrm{~nm}$ and $\mathrm{nL}_{\mathrm{w}}$ at 412 and $554 \mathrm{~nm}$ are shown in Fig. 8c, e and g; the MODIS standard aerosol products (Fig. 8a) and OC products (Fig. 8b, d and f) are also added as comparisons. In general, the retrieved AOTs are mostly similar to those of MODIS aerosol products, as well as OC products, where the high aerosol loading around the Bohai Sea can be observed in Fig. 8a and c; however, the MODIS AC scheme cannot produce useful AOT data in this heavy aerosol area (Fig. 8b). In regards to the estimated $\mathrm{nL}_{\mathrm{w}}$ at 412 and $554 \mathrm{~nm}$, there are also good consistencies between MODIS OC products and those derived from the simultaneous retrieval approach, while the retrieved $\mathrm{nL}_{\mathrm{w}}$ values at $412 \mathrm{~nm}$ from MODIS OC products are reported to be negative values in the north of the Yellow Sea (Fig. 8d), where such a case can be avoided using the current scheme shown in Fig. 8e.

\subsection{Retrieval results based on sunglint observation}

In this study, the reflectance and transmission functions of the ocean surface are calculated using the formulation of Nakajima and Takana (1983); these functions are derived using wind speed values, which is similar to the Cox-Munk ocean model (Cox and Munk, 1954) but without offset. To investigate the retrieval accuracy using sunglint observation, a simulation retrieval experiment is conducted firstly. The simulation is run for a solar zenith angle of $45^{\circ}$ and viewing angle in the total specular reflection and out-of-sunglint conditions. Five total AOTs at $550 \mathrm{~nm}$ of $0.039,0.084,0.123$, 0.181 and 0.346 are used (Knobelspiesse et al., 2012) with the fine-mode fraction of $70 \%$. The ocean is modeled with a low wind speed of $3 \mathrm{~m} \mathrm{~s}^{-1}$ (Ottaviani et al., 2013) and values of Chl of $0.5 \mathrm{mg} \mathrm{m}^{-3}$, respectively, where sediment and CDOM are neglected. The accuracy of the satellite radiance 

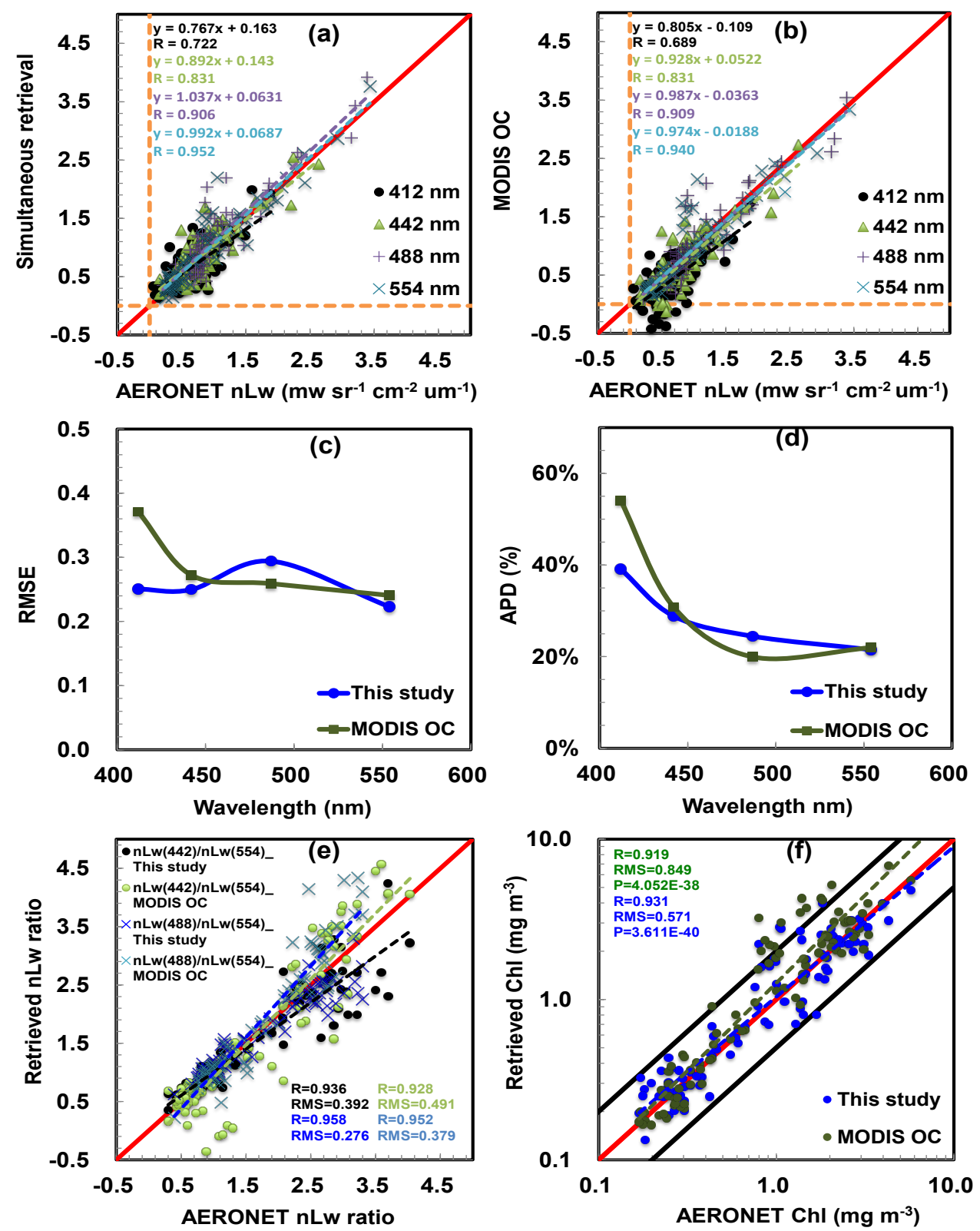

Figure 7. Comparison of jointly retrieved $\mathrm{nL}_{\mathrm{w}}$ at 412, 442, 488 and $554 \mathrm{~nm}$ from the simultaneous retrieval algorithm (a) and MODIS OC products (b) using measurements out of sunglint with AERONET in situ observation. Statistical values of RMSE (c), APD (d), band ratios of $\mathrm{nL}_{\mathrm{W}}(442) / \mathrm{nL}_{\mathrm{W}}(554)$ and $\mathrm{nL}_{\mathrm{W}}(488) / \mathrm{nL}_{\mathrm{W}}$ (554) (e) and Chl (f) results retrieved by the two approaches compared with AERONET-OC products. The upper and lower black lines of panel (f) are $1: 2$ and $2: 1$, respectively. The dashed lines are denoted as regression lines, which correspond to the retrieved results with the same colors.

in the measurement is set to $2 \%$. Figure 9 shows the retrieval uncertainties in different AOT values from in glint and out of glint observation using eight MODIS wavelength measurements. It is demonstrated that the retrieval uncertainty of coarse AOT increases significantly in high-value conditions when the observation is covered in sunglint, while the relative magnitude of the uncertainty of fine AOT is not surprising with less than $25 \%$ on average from the sunglint measurement. A more accurate retrieval of wind speed is achieved using sunglint observations due to the significant sensitivity to measurements (the a priori value of wind speed is set to $5 \mathrm{~m} \mathrm{~s}^{-1}$ ). For the determination of chlorophyll $a$ concentration, there is not a significant difference of retrieval uncertainty using sunglint or not, it is caused by the inconspicuous influence of sunglint signal on the underwater field, which is similar to the study of Ottaviani et al. (2013) using 

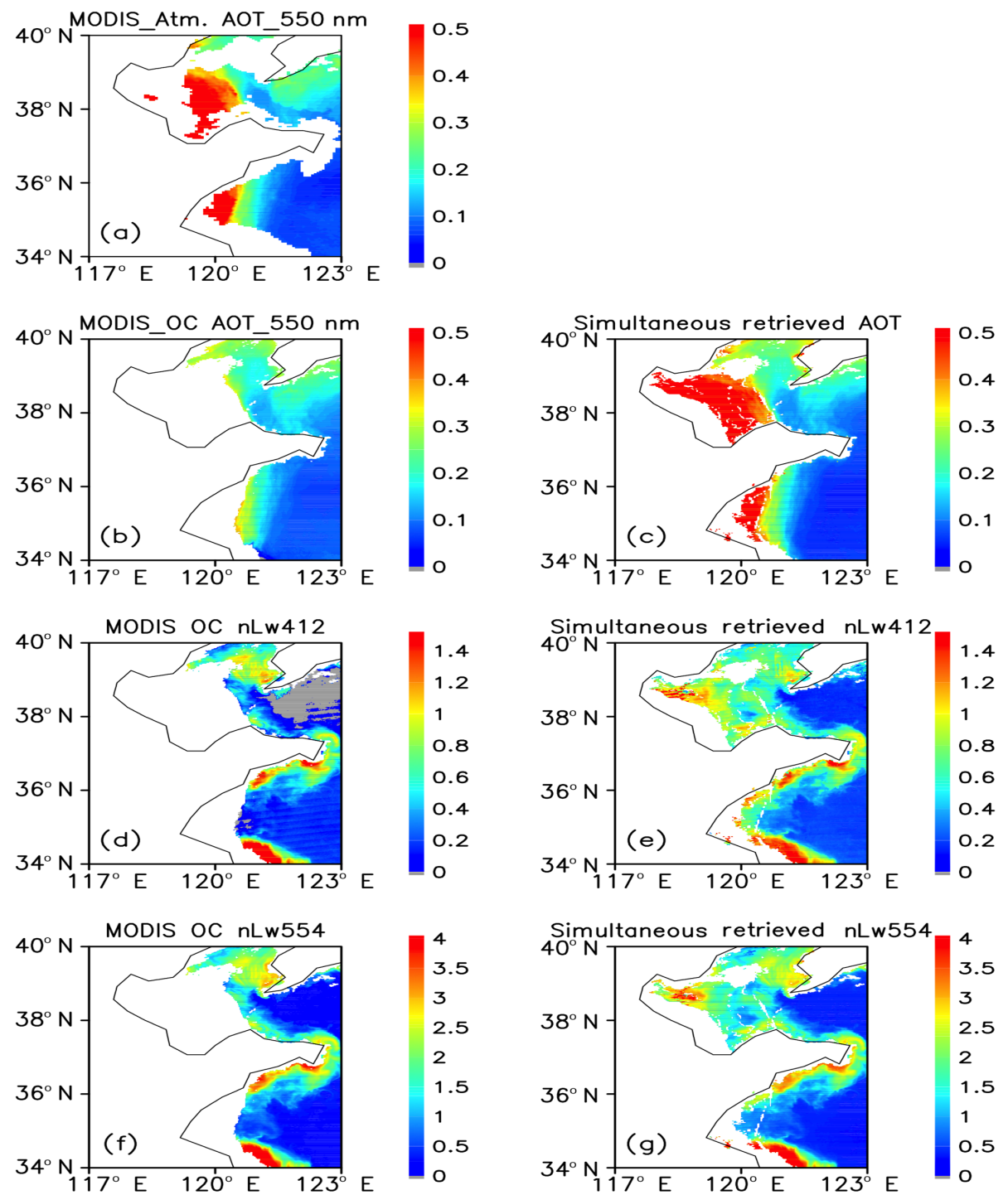

Figure 8. Comparison of simultaneously retrieved satellite AOT at $550 \mathrm{~nm}$ and $\mathrm{nL}_{\mathrm{w}}\left(\mathrm{mw} \mathrm{sr} \mathrm{cm}^{-1} \mu \mathrm{m}^{-1}\right)$ at 412 and $554 \mathrm{~nm}$ with MODIS operational products over the East China Sea on 18 October 2011. (a) MODIS aerosol AOT products; (b, d, f) MODIS ocean color AOT and $\mathrm{nL}_{\mathrm{w}}$ products; (c, e, g) simultaneously retrieved $\mathrm{AOT}$ and $\mathrm{nL}_{\mathrm{w}}$ in this study.

more observation information. Therefore, relatively accurate retrieval of AOT can be determined based on the simultaneous retrieval of wind speed in sunglint measurements, when the aerosol is dominated by fine-mode particles or low-value conditions.

The inversion algorithm is then applied to investigate the accuracy of retrieved AOT and $\mathrm{nL}_{\mathrm{w}}$ using real satellite data covered in the sunglint region. The NCEP data are used as the priori constrain of wind speed values in this study. Figure 10 shows the comparisons of retrieved AOT values, which can be jointly estimated from these two approaches, to the AERONET observations with the number of match-up pairs being 18. Results indicate that the sunglint does contaminate the estimation of AOT, where the accuracy was reduced by up to $15 \%$ or more compared with those using out-of-sunglint measurements. Generally, the derived AOTs at $550 \mathrm{~nm}$ from the current algorithm are much more consistent with AERONET-OC data than those obtained from the MODIS standard AC algorithm shown in Fig. 10a and b, where the reported AOTs are mostly overestimated in sunglint regions. Such overestimation conditions also occurred in other bands (shown in Fig. 10c). In contrast to the retrieval cases based on the measurements out of sunglint (Fig. 6d), the mean AOT values from the standard AC scheme are much larger than AERONET-OC data at NIR bands. In general, the estimated AOTs from the current scheme compare well with the in situ products, from which the RMSE and APD are reduced by up to 0.023 and $45.25 \%$ in blue bands and 0.043 and $70.14 \%$ in green and even NIR bands, respectively, when compared with those derived from 

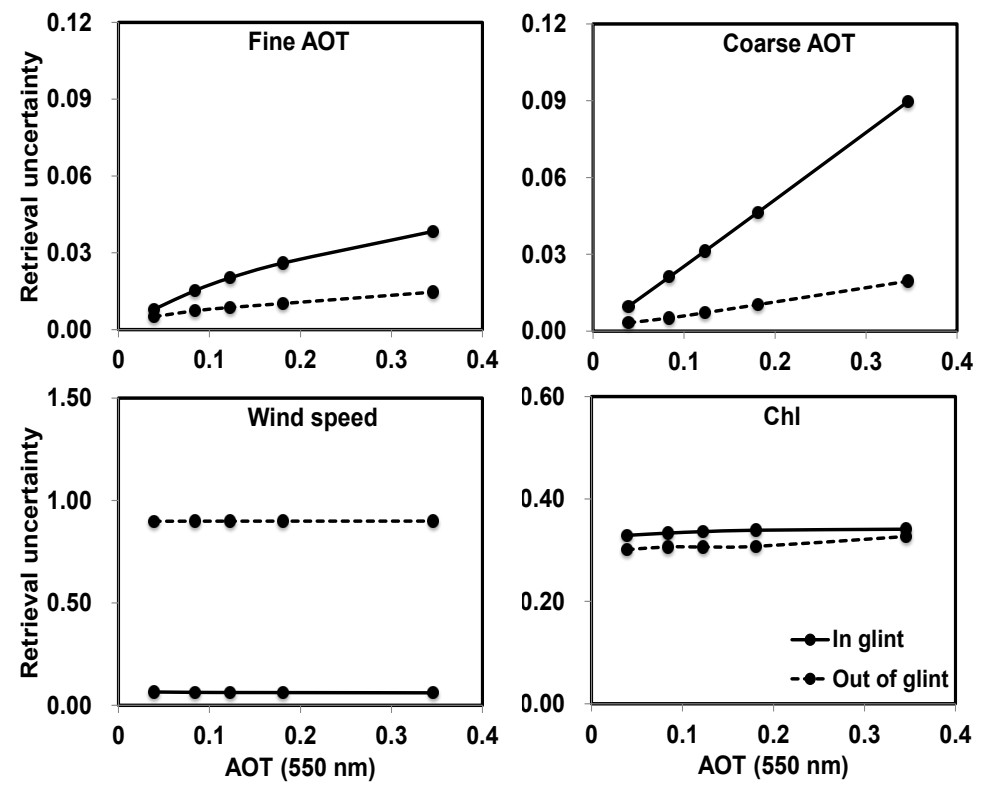

Figure 9. Simulated retrieval absolute uncertainties (components of $\hat{\mathbf{S}}$ ) as a function of total AOT at $550 \mathrm{~nm}$. Results using sunglint observations are shown in solid lines, and those from out of sunglint are in dashed lines.
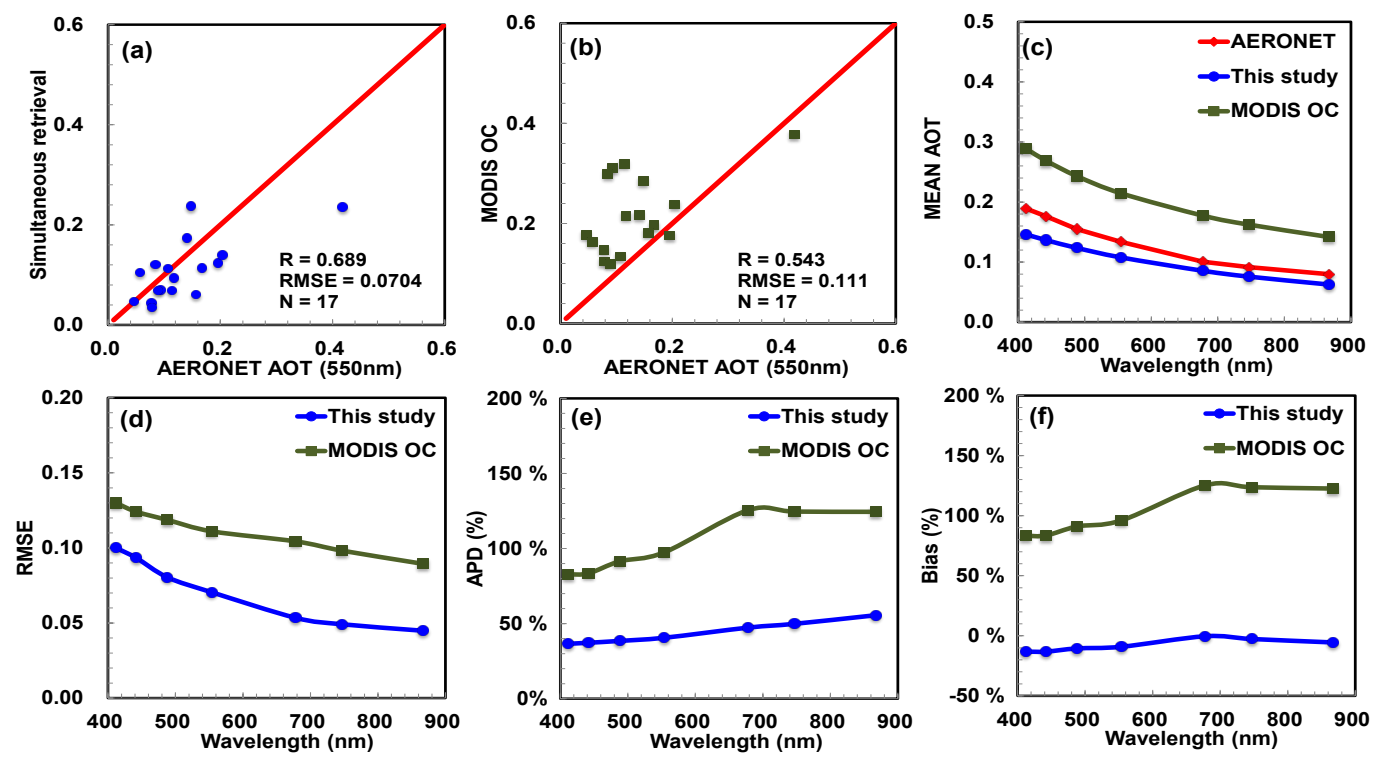

Figure 10. Similar to Fig. 6 but using the satellite measurements covered in sunglint.

the standard AC algorithm shown in Fig. 10d and e. This could be caused by the underestimation of the contribution of the direct solar beam reflection from the ocean surface to the satellite-received signals, and more AOT is reciprocally estimated. In contrast, wind speed is not fixed but simultaneously retrieved in this study to compensate the estimated specular reflectance error using the Cox-Munk model (Cox and Munk, 1954) even though this model has been proven to show good performance validated by satellite measurements (Zhang and Wang, 2010). However, the simultaneous algorithm seems to overcorrect the sunglint contamination to estimate the AOT values a lot lower than the standard AC scheme in high aerosol loading conditions, just as shown in Fig. 10a and $b$.

For the retrieval of $\mathrm{nL}_{\mathrm{w}}$ in sunglint regions, the optimal estimation algorithm has a significant improvement in the determination of $\mathrm{nL}_{\mathrm{w}}$ at $412 \mathrm{~nm}$ with lower RMSE and APD values and slightly better inversion of $\mathrm{nL}_{\mathrm{w}}$ at 442 and $554 \mathrm{~nm}$, but worse retrieval of $\mathrm{nL}_{\mathrm{w}}$ at $488 \mathrm{~nm}$ than those from the standard $\mathrm{AC}$ scheme in contrast to in situ measurements 

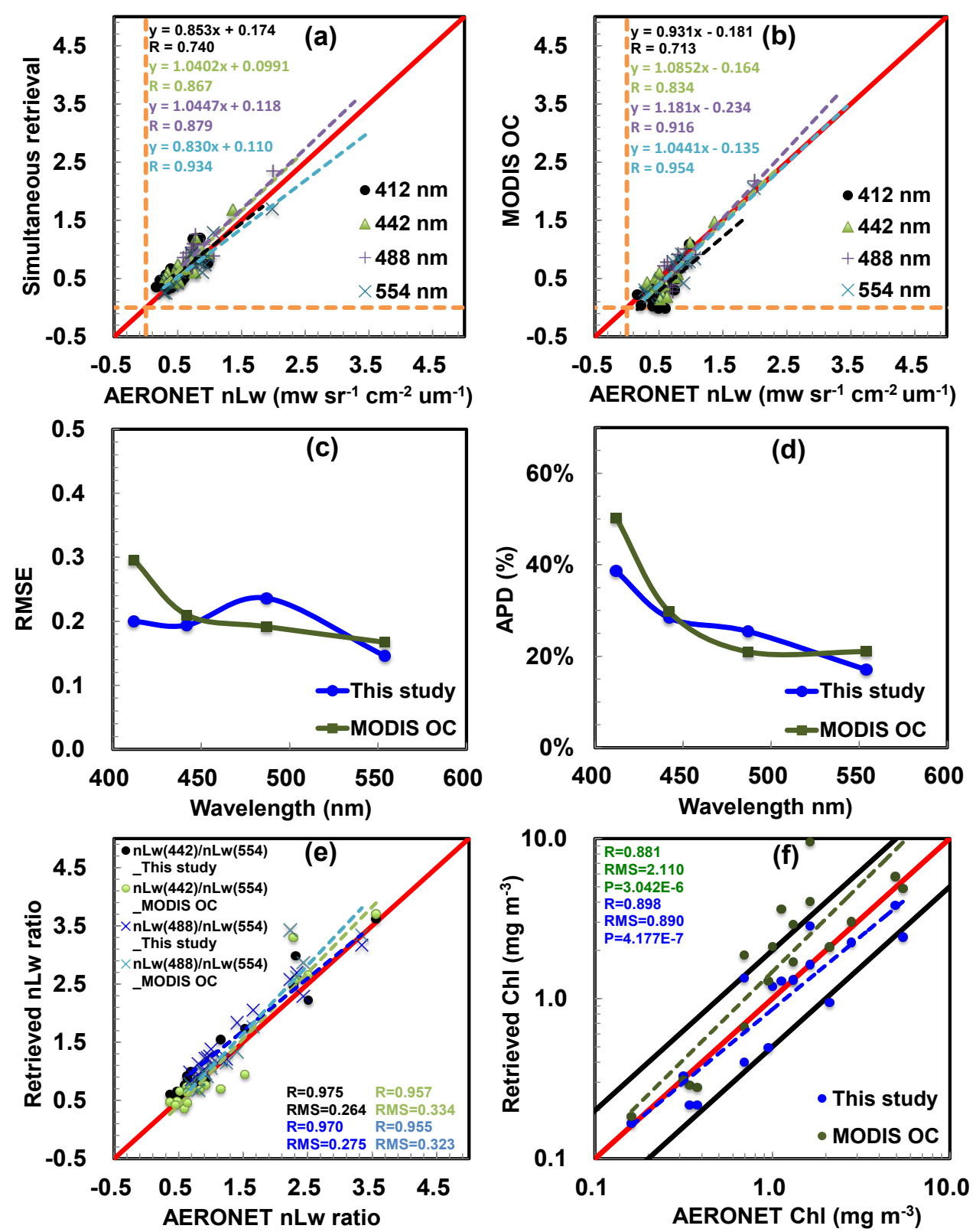

Figure 11. Similar to Fig. 7 but using the satellite measurements covered in sunglint.

shown in Fig. 11a-d. Such situations are also similar to that using the satellite measurements out of sunglint (Fig. 7cd). In regards to the band ratios of $\mathrm{nL}_{\mathrm{w}}(443) / \mathrm{nL}_{\mathrm{w}}$ (554) and $\mathrm{nL}_{\mathrm{w}}(487) / \mathrm{nL}_{\mathrm{w}}$ (554), the current algorithm estimates lower values of RMSE but higher values of APD than the MODIS standard AC algorithm (Fig. 11e) compared with in situ products. The retrieved $\mathrm{Chl}$ in this study has a slightly better correlation coefficient and a smaller RMSE and APD than MODIS OC products in contrast to AERONET-OC data. It is shown that there are several cases where Chl values are much more overestimated (shown in Fig. 11f), which may be caused by the overestimation of atmospheric contribu- tion in the atmospheric correction procedure, where most of them occur at the Galata_Platform site. Compared with the AERONET-OC products, the MODIS operational AC scheme tends to overestimate the $\mathrm{Chl}$ values, which is contrary to the current algorithm, which seemed to underestimate the $\mathrm{Chl}$ values generally, such as those demonstrated in Figs. $7 \mathrm{f}$ and $11 \mathrm{f}$, using satellite measurements covering outof-sunglint and in-sunglint observations, respectively. 


\section{Conclusions and outlooks}

Satellite remote sensing of aerosols and water-leaving radiance in coastal waters remains a challenging problem due to the difficulty of estimating the path radiance over turbid coastal waters. Besides, the direct sunglint reflected on the ruffled ocean also influences the retrieval accuracy due to its contamination in satellite measurements. Standard AC schemes of ocean color, such as the ones implemented for the MODIS instrument, use NIR bands or combined NIR and SWIR bands to retrieve the aerosol optical properties based on the assumption of null water-leaving radiance, and then extrapolate to the shorter wavelengths using the derived aerosol modes from precalculated look-up tables. However, the retrieved aerosol spectral properties are not always fully consistent with the observations at shorter wavelengths using the conventional AC algorithm since the AOT values are sometimes reported to be overestimated and the derived water-leaving radiance is occasionally negative in those bands.

To deal with these problems and make full use of spectral information as well as shorter band measurements in the joint determination of aerosol optical thickness and water-leaving radiance, a different algorithm that simultaneously retrieves AOT and $L_{\mathrm{w}}$ from multispectral measurements is developed in this study. In this algorithm, we use a coupled atmosphereocean RT model combined with a comprehensive oceanic bio-optical module, in consideration of influence of sediment and CDOM, as well as temperature and salinity, as the forward RT simulation. Then, an optimization approximation scheme is developed to adjust the retrieved parameters, consisting of AOT of fine, sea spray and dust particles, soot fraction in fine particles, wind speed, chlorophyll $a$ concentration, sediment and CDOM, to fit observation with spectral measurements in an iterative manner. The adjustment of retrieved parameters allows the retrieval of water-leaving radiance calculated by the developed oceanic module simultaneously.

We derived the system's vicarious calibration coefficients using ground-truth measurements for the current algorithm firstly. The following retrievals are then performed based on the calibration results. Validation is carried out using the AERONET-OC products selected from eight sites, distributed over different ocean regions, to investigate the accuracy and flexibility of the simultaneous retrieval algorithm in determining AOT and $\mathrm{nL}_{\mathrm{w}}$. For the retrieval using satellite measurements out of sunglint, a good agreement between results is obtained at each station, including in the cases of high aerosol loading and turbid waters, such as at Ieodo_Station in the Yellow Sea. Generally, the retrieved spectral AOT values are more consistent with the AERONET products, particularly for the AOT in visible bands, with the APD reduced by up to $10 \%$ compared with those using the standard AC scheme, where derived AOT values tend to be overestimated. At NIR bands, the two algorithms have a sim- ilar estimation of AOT. For the retrieval of $\mathrm{nL}_{\mathrm{w}}$, over atmospheric overcorrection can be avoided in order to have a significant improvement of the inversion of $\mathrm{nL}_{\mathrm{w}}$ at $412 \mathrm{~nm}$ and slightly better estimation of $\mathrm{nL}_{\mathrm{w}}$ at $443 \mathrm{~nm}$. Band ratios of $\mathrm{nL}_{\mathrm{w}}(443) / \mathrm{nL}_{\mathrm{w}}(554)$ and $\mathrm{nL}_{\mathrm{w}}(488) / \mathrm{nL}_{\mathrm{w}}(554)$ derived from the current algorithm have a lower RMSE and APD in order to obtain a better estimation of Chl than those from the standard AC scheme, with the APD of Chl decreased by approximately $5 \%$. Similar situations are also occurred using satellite measurements covered in sunglint, where the accuracy of derived AOT is improved more significantly than that from the standard AC algorithm, where AOT values are mostly overestimated. It may be that the wind speed, which has significant weighting function in sunglint measurements, is also simultaneously retrieved in this study to compensate the specular reflectance error from the ocean surface. On the other hand, the standard AC scheme has a better retrieval of $\mathrm{nL}_{\mathrm{w}}$ at $488 \mathrm{~nm}$ generally, with the APD value of $5 \%$ lower than that of the current algorithm, prompting a further improvement of the oceanic bio-optical module in this study.

In the future, optimization of the bio-optical model should be conducted using more extensive in situ observation data, such as the study of Maritorena et al. (2002), to have better modeling of the radiation process in the ocean system, since small variations of inherent optical properties of ocean substance may translate into large $\mathrm{nL}_{\mathrm{w}}$ retrieval errors. Moreover, improvement of the algorithm by adopting a multipixel constraining technique (Dubovik et al., 2011; Xu et al., 2016; Hashimoto and Nakajima, 2017) is also part of our ongoing study. Since the current algorithm adopts the coupled RT model and optimization approach to derive AOT and $\mathrm{nL}_{\mathrm{w}}$ in an iteration manner, the computation efficiency will be much lower than that of the standard AC schemes. In order to overcome this problem, a neural network solver, which has been successfully implemented in the estimation of solar radiation (Takenaka et al., 2011) from geostationary satellite measurement and joint retrieval of AOT and ground surface albedo over land (Hashimoto et al., 2017), is being constructed to accelerate the algorithm by a factor of several thousand, and a related study will be explicated in another work.

Data availability. The simultaneous retrieved AOT and $\mathrm{nL}_{\mathrm{W}}$ data can be obtained from the corresponding author upon request.

Competing interests. The authors declare that they have no conflict of interest.

Acknowledgements. This work was supported by funds from MOEJ\&JAXA/GOSAT\&GOSAT2， JST/CREST/JPMJCR15K4, JAXA/EarthCARE\&GCOM-C, MOEJ/ERTDF/S-12, National Natural Science Foundation of China (NSFC) (41590875), Key Laboratory of Meteorological Disaster of Ministry of Education 
and Nanjing University of Information Science and Technology (KLME1509). The authors express their sincere thanks to the personnel and relevant PIs (Giuseppe Zibordi, Brent Holben, Thomas Schroeder, Young-Je Park, Hak-Yeol You, Dimitry Van der Zande, Burton Jones and Curtiss Davis) for their continuous effort in establishing and maintaining the AERONET-OC sites used in this investigation. The Australian Integrated Marine Observing System (IMOS) and CSIRO are acknowledged for funding the Lucinda AERONET-OC site. The MODIS, OMI and NCEP science teams are acknowledged for releasing the data. We also thank Chuanmin $\mathrm{Hu}$ and Robert Frouin for their insightful suggestions to improve our work. We thank the one anonymous reviewer and Zhanqing Li for providing constructive review comments, as well as Thomas Schroeder and Andrew Mark Sayer for their valuable short comments.

Edited by: Jianping Huang

Reviewed by: Zhanqing Li and one anonymous referee

\section{References}

Ackerman, S. A., Strabala, K. I., Menzel, W. P., Frey, R. A., Moeller, C. C., and Gumley, L. E.: Discriminating clear sky from clouds with MODIS, J. Geophys. Res., 103, 32141-32157, 1998.

Ahmad, Z., Franz, B. A., McClain, C. R., Kwiatkowska, E. J., Werdell, J., Shettle, E. P., and Holben, B. N.: New aerosol models for the retrieval of aerosol optical thickness and normalized water-leaving radiances from the SeaWiFS and MODIS sensors over coastal regions and open oceans, Appl. Optics, 49, 5545$5560,2010$.

Antoine, D. and Morel, A.: A multiple scattering algorithm for atmospheric correction of remotely sensed ocean colour (MERIS instrument): principle and implementation for atmospheres carrying various aerosols including absorbing ones, Int. J. Remote Sens., 20, 1875-1916, 1999.

Bailey, S. W., Franz, B. A., and Werdell, P. J.: Estimation of nearinfrared water-leaving reflectance for satellite ocean color data processing, Opt. Express, 18, 7521-7527, 2010.

Boucher, O., Randall, D., Artaxo, P., Bretherton, C., Feingold, G., Forster, P., Kerminen, V.-M., Kondo, Y., Liao, H., Lohmann, U., Rasch, P., S.K, S., Sherwood, S., B., S., and Zhang, X. Y.: Clouds and aerosols, in: Climate Change 2013: The Physical Science Basis. Contribution of Working Group I to the Fifth Assessment Report of the Intergovernmental Panel on Climate Change, Cambridge University Press, Cambridge, United Kingdom and New York, NY, USA, 571-657, 2013.

Bréon, F. M. and Henriot, N.: Spaceborne observations of ocean glint reflectance and modeling of wave slope distributions, J. Geophys. Res., 111, C06005, https://doi.org/10.1029/2005JC003343, 2006.

Bricaud, A. and Morel, A.: Atmospheric corrections and interpretation of marine radiances in CZCS imagery: use of a reflectance model, Oceanol. Acta, 7, 33-50, 1987.

Bricaud, A., Morel, A., and Prieur, L.: Absorption by dissolved organic matter of the sea (yellow substance) in the UV and visible domains, Limnol. Oceanogr., 26, 43-53, 1981.

Bricaud, A., Babin, M., Morel, A., and Claustre, H.: Variability in the chlorophyll-specific absorption coefficients of natural phyto- plankton: analysis and parameterization, J. Geophys. Res., 100, 13321-13332, 1995.

Chami, M., Lafrance, B., Fougnie, B., Chowdhary, J., Harmel, T., and Waquet, F.: OSOAA: a vector radiative transfer model of coupled atmosphere-ocean system for a rough sea surface application to the estimates of the directional variations of the water leaving reflectance to better process multi-angular satellite sensors data over the ocean, Opt. Express, 23, 27829-27852, 2015.

Chomko, R. M. and Gordon, H. R.: Atmospheric correction of ocean color imagery: use of the Junge power-law aerosol size distribution with variable refractive index to handle aerosol absorption, Appl. Optics, 37, 5560-5572, 1998.

Chowdhary, J., Cairns, B., and Travis, L. D.: Contribution of waterleaving radiances to multiangle, multispectral polarimetric observations over the open ocean: bio-optical model results for case 1 waters, Appl. Optics, 45, 5542-5567, 2006.

Chust, G. and Sagarminaga, Y.: The multi-angle view of MISR detects oil slicks under sun glitter conditions, Remote Sens. Environ., 107, 232-239, 2007.

Cox, C. and Munk, W.: Measurement of the roughness of the sea surface from photographs of the sun's glitter, J. Opt. Soc. Am., 44, 838-850, 1954.

Doerffer, R. and Fischer, J.: Concentrations of chlorophyll, suspended matter, and gelbstoff in case II waters derived from satellite coastal zone color scanner data with inverse modeling methods, J. Geophys. Res.-Oceans, 99, 7457-7466, 1994.

Dubovik, O. and King, M. D.: A flexible inversion algorithm for retrieval of aerosol optical properties from Sun and sky radiance measurements, J. Geophys. Res.-Atmos., 105, 20673-20696, 2000.

Dubovik, O., Holben, B., Lapyonok, T., Sinyuk, A., Mishchenko, M., Yang, P., and Slutsker, I.: Non-spherical aerosol retrieval method employing light scattering by spheroids, Geophys. Res. Lett., 29, 54-1-54-4, 2002.

Dubovik, O., Lapyonok, T., Kaufman, Y. J., Chin, M., Ginoux, P., Kahn, R. A., and Sinyuk, A.: Retrieving global aerosol sources from satellites using inverse modeling, Atmos. Chem. Phys., 8, 209-250, https://doi.org/10.5194/acp-8-209-2008, 2008.

Dubovik, O., Herman, M., Holdak, A., Lapyonok, T., Tanré, D., Deuzé, J. L., Ducos, F., Sinyuk, A., and Lopatin, A.: Statistically optimized inversion algorithm for enhanced retrieval of aerosol properties from spectral multi-angle polarimetric satellite observations, Atmos. Meas. Tech., 4, 975-1018, https://doi.org/10.5194/amt-4-975-2011, 2011.

Fan, Y., Li, W., Gatebe, C. K., Jamet, C., Zibordi, G., Schroeder, T., and Stamnes, K.: Atmospheric correction over coastal waters using multilayer neural networks, Remote Sens. Environ., 199, 218-240, 2017.

Fell, F. and Fischer, J.: Numerical simulation of the light field in the atmosphere-ocean system using the matrix-operator method, J. Quant. Spectrosc. Ra., 69, 351-388, 2001.

Fischer, J. and Grassl, H.: Radiative transfer in an atmosphere - ocean system: an azimuthally dependent matrix-operator approach, Appl. Optics, 23, 1032-1039, 1984.

Fougnie, B., Deschamps, P.-Y., and Frouin, R.: Vicarious calibration of the POLDER ocean color spectral bands using in situ measurements, IEEE T. Geosci. Remote, 37, 1567-1574, 1999.

Fournier, G. R. and Forand, J. L.: Analytic phase function for ocean water, Proc. SPIE 2258, 194-201, 1994. 
Franz, B. A., Bailey, S. W., Werdell, P. J., and McClain, C. R.: Sensor-independent approach to the vicarious calibration of satellite ocean color radiometry, Appl. Optics, 46, 5068-5082, 2007.

Frouin, R. and Pelletier, B.: Bayesian methodology for inverting satellite ocean-color data, Remote Sens Environ., 159, 332-360, 2015.

Frouin, R., Deschamps, P.-Y., Gross-Colzy, L., Murakami, H., and Nakajima, T. Y.: Retrieval of chlorophyll-a concentration via linear combination of ADEOS-II Global Imager data, J. Oceanogr., 62, 331-337, 2006.

Fukushima, H., Higurashi, A., Mitomi, Y., Nakajima, T., Noguchi, T., Tanaka, T., and Toratani, M.: Correction of atmospheric effect on ADEOS/OCTS ocean color data: algorithm description and evaluation of its performance, J. Oceanogr., 54, 417-430, 1998.

Gao, B.-C., Montes, M. J., Ahmad, Z., and Davis, C. O.: Atmospheric correction algorithm for hyperspectral remote sensing of ocean color from space, Appl. Optics, 39, 887-896, 2000.

Gordon, H. R.: In-orbit calibration strategy for ocean color sensors, Remote Sens. Environ., 63, 265-278, 1998.

Gordon, H. R. and Clark, D. K.: Clear water radiances for atmospheric correction of coastal zone color scanner imagery, Appl. Optics, 20, 4175-4180, 1981.

Gordon, H. R. and Morel, A. Y.: Remote Assessment of Ocean Color for Interpretation of Satellite Visible Imagery: a Review, Springer: New York, NY, USA, 114 pp., 1983.

Gordon, H. R. and Wang, M.: Retrieval of water-leaving radiance and aerosol optical thickness over the oceans with SeaWiFS: a preliminary algorithm, Appl. Optics, 33, 443-452, 1994.

Gordon, H. R., Brown, J. W., and Evans, R. H.: Exact Rayleigh scattering calculations for use with the Nimbus-7 coastal zone color scanner, Appl. Optics, 27, 862-871, 1988.

Goyens, C., Jamet, C., and Schroeder, T.: Evaluation of four atmospheric correction algorithms for MODIS-Aqua images over contrasted coastal waters, Remote Sens. Environ., 131, 63-75, 2013.

Hale, G. M. and Querry, M. R.: Optical constants of water in the 200-nm to 200- $\mu \mathrm{m}$ wavelength region, Appl. Optics, 12, 555$563,1973$.

Harmel, T. and Chami, M.: Determination of sea surface wind speed using the polarimetric and multidirectional properties of satellite measurements in visible bands, Geophys. Res. Lett., Lett., 39, L19611, https://doi.org/10.1029/2012GL053508, 2012.

Hasekamp, O. P., Litvinov, P., and Butz, A.: Aerosol properties over the ocean from PARASOL multiangle photopolarimetric measurements, J. Geophys. Res., 116, D14204, https://doi.org/10.1029/2010JD015469, 2011.

Hashimoto, M. and Nakajima, T.: Development of a remote sensing algorithm to retrieve atmospheric aerosol properties using multi-wavelength and multi-pixel information, J. Geophys. Res.-Atmos., 122, 6347-6378, https://doi.org/10.1002/2016JD025698, 2017.

Hashimoto, M., Takenaka, H., Higurashi, A., and Nakajima, T.: Adaptation of an aerosol retrieval algorithm using multiwavelength and multi-pixel information of satellites (MWPM) to GOSAT/TANSO-CAI, AGU Fall Meeting, New Orleans, USA, 11-15 December 2017, A21A-2152, 2017.
He, X., Bai, Y., Zhu, Q., and Gong, F.: A vector radiative transfer model of coupled ocean-atmosphere system using matrixoperator method for rough sea-surface, J. Quant. Spectrosc. Ra., 111, 1426-1448, 2010.

He, X. Q., Bai, Y., Pan, D. L., Tang, J. W., and Wang, D. F.: Atmospheric correction of satellite ocean color imagery using the ultraviolet wavelength for highly turbid waters, Opt. Express, 20, 20754-20770, https://doi.org/10.1364/oe.20.020754, 2012.

Higurashi, A. and Nakajima, T.: Development of a two-channel aerosol retrieval algorithm on a global scale using NOAA AVHRR, J. Atmos. Sci., 56, 924-941, 1999.

Holben, B., Eck, T., Slutsker, I., Tanre, D., Buis, J., Setzer, A., Vermote, E., Reagan, J., Kaufman, Y., and Nakajima, T.: AERONET - a federated instrument network and data archive for aerosol characterization, Remote Sens. Environ., 66, 1-16, 1998.

$\mathrm{Hu}, \mathrm{C} .:$ An empirical approach to derive MODIS ocean color patterns under severe sun glint, Geophys. Res. Lett., 38, L01603, https://doi.org/10.1029/2010GL045422, 2011.

$\mathrm{Hu}, \mathrm{C}$., Carder, K. L., and Muller-Karger, F. E.: Atmospheric correction of SeaWiFS imagery over turbid coastal waters: a practical method, Remote Sens. Environ., 74, 195-206, 2000.

Hu, C., Li, X., Pichel, W. G., and Muller-Karger, F. E.: Detection of natural oil slicks in the NW Gulf of Mexico using MODIS imagery, Geophys. Res. Lett., 36, L01604, https://doi.org/10.1029/2008GL036119, 2009.

Huang, J., Wang, T., Wang, W., Li, Z., and Yan, H.: Climate effects of dust aerosols over East Asian arid and semiarid regions, J. Geophys. Res.-Atmos., 119, 11398-11416, 2014.

Huibers, P. D.: Models for the wavelength dependence of the index of refraction of water, Appl. Optics, 36, 3785-3787, 1997.

Huot, Y., Morel, A., Twardowski, M. S., Stramski, D., and Reynolds, R. A.: Particle optical backscattering along a chlorophyll gradient in the upper layer of the eastern South Pacific Ocean, Biogeosciences, 5, 495-507, https://doi.org/10.5194/bg5-495-2008, 2008.

Kahn, R. A., Sayer, A. M., Ahmad, Z., and Franz, B. A.: The sensitivity of SeaWiFS ocean color retrievals to aerosol amount and type, J. Atmos. Ocean. Tech., 33, 1185-1209, 2016.

Jamet, C., Loisel, H., Kuchinke, C. P., Ruddick, K., Zibordi, G., and Feng, H.: Comparison of three SeaWiFS atmospheric correction algorithms for turbid waters using AERONET-OC measurements, Remote Sens. Environ., 115, 1955-1965, 2011.

Jeong, M. J. and Li, Z.: Quality, compatibility, and synergy analyses of global aerosol products derived from the advanced very high resolution radiometer and Total Ozone Mapping Spectrometer, J. Geophys. Res., 110, D10S08, https://doi.org/10.1029/2004JD004647, 2005.

Jin, Z., Charlock, T. P., Rutledge, K., Stamnes, K., and Wang, Y.: Analytical solution of radiative transfer in the coupled atmosphere-ocean system with a rough surface, Appl. Optics, 45, 7443-7455, 2006.

Kaufman, Y., Martins, J., Remer, L., Schoeberl, M., and Yamasoe, M.: Satellite retrieval of aerosol absorption over the oceans using sunglint, Geophys. Res. Lett., 29, 34-31-34-34, 2002.

Knobelspiesse, K., Cairns, B., Mishchenko, M., Chowdhary, J., Tsigaridis, K., van Diedenhoven, B., Martin, W., Ottaviani, M., and Alexandrov, M.: Analysis of fine-mode aerosol retrieval capabilities by different passive remote sensing instrument designs, Opt. Express, 20, 21457-21484, 2012. 
Kokhanovsky, A. A., Budak, V. P., Cornet, C., Duan, M., Emde, C., Katsev, I. L., Klyukov, D. A., and Korkin, S. V.: Benchmark results in vector atmospheric radiative transfer, J. Quant. Spectrosc. Ra., 111, 1931-1946, 2010.

Kou, L., Labrie, D., and Chylek, P.: Refractive indices of water and ice in the 0.65-to 2.5- $\mu \mathrm{m}$ spectral range, Appl. Optics, 32, 35313540, 1993.

Kuchinke, C. P., Gordon, H. R., and Franz, B. A.: Spectral optimization for constituent retrieval in Case 2 waters I: implementation and performance, Remote Sens. Environ., 113, 571-587, 2009.

Levenberg, K.: A method for the solution of certain non-linear problems in least squares, Q. Appl. Math., 2, 164-168, 1944.

Li, W., Stamnes, K., Spurr, R., and Stamnes, J.: Simultaneous retrieval of aerosol and ocean properties by optimal estimation: seaWiFS case studies for the Santa Barbara Channel, Int. J. Remote Sens., 29, 5689-5698, 2008.

Li, Z., Zhao, X., Kahn, R., Mishchenko, M., Remer, L., Lee, K.H., Wang, M., Laszlo, I., Nakajima, T., and Maring, H.: Uncertainties in satellite remote sensing of aerosols and impact on monitoring its long-term trend: a review and perspective, Ann. Geophys., 27, 2755-2770, https://doi.org/10.5194/angeo27-2755-2009, 2009

Mao, Z. H., Chen, J. Y., Hao, Z. Z., Pan, D. L., Tao, B. Y., and Zhu, Q. K.: A new approach to estimate the aerosol scattering ratios for the atmospheric correction of satellite remote sensing data in coastal regions, Remote Sens. Environ., 132, 186-194, https://doi.org/10.1016/j.rse.2013.01.015, 2013.

Maritorena, S., Siegel, D. A., and Peterson, A. R.: Optimization of a semianalytical ocean color model for global-scale applications, Appl. Optics, 41, 2705-2714, 2002.

Marquardt, D. W.: An algorithm for least-squares estimation of nonlinear parameters, SIAM J. Appl. Math., 11, 431-441, 1963.

Mélin, F. and Zibordi, G.: Vicarious calibration of satellite ocean color sensors at two coastal sites, Appl. Optics, 49, 798-810, 2010

Mobley, C. D.: Light and Water: Radiative Transfer in Natural Waters, Academic Press, New York, USA, , 1994.

Mobley, C. D.: Ocean Optics Web Book, http://www. oceanopticsbook.info, last access: 21 May 2014.

Mobley, C. D., Gentili, B., Gordon, H. R., Jin, Z., Kattawar, G. W., Morel, A., Reinersman, P., Stamnes, K., and Stavn, R. H.: Comparison of numerical models for computing underwater light fields, Appl. Optics, 32, 7484-7504, 1993.

Morel, A.: Optical properties of pure water and pure sea water, Optical Aspects Oceanography, 1, 22 pp., 1974.

Morel, A. and Maritorena, S.: Bio-optical properties of oceanic waters: a reappraisal, J. Geophys. Res.-Oceans, 106, 7163-7180, 2001

Morrison, J. R. and Nelson, N. B.: Seasonal cycle of phytoplankton UV absorption at the Bermuda Atlantic Time-series Study (BATS) site, Limnol. Oceanogr., 49, 215-224, 2004.

Murakami, H., Yoshida, M., Tanaka, K., Fukushima, H., Toratani, M., Tanaka, A., and Senga, Y.: Vicarious calibration of ADEOS-2 GLI visible to shortwave infrared bands using global datasets, IEEE T. Geosci. Remote, 43, 1571-1584, 2005.

Nakajima, T. and Higurashi, A.: AVHRR remote sensing of aerosol optical properties in the Persian Gulf region, summer 1991, J. Geophys. Res.-Atmos., 102, 16935-16946, 1997.
Nakajima, T. and Tanaka, M.: Effect of wind-generated waves on the transfer of solar radiation in the atmosphere-ocean system, J. Quant. Spectrosc. Ra., 29, 521-537, 1983.

Nakajima, T. and Tanaka, M.: Matrix formulations for the transfer of solar radiation in a plane-parallel scattering atmosphere, J. Quant. Spectrosc. Ra., 35, 13-21, 1986.

Nakajima, T. and Tanaka, M.: Algorithms for radiative intensity calculations in moderately thick atmospheres using a truncation approximation, J. Quant. Spectrosc. Ra., 40, 51-69, 1988.

Nakajima, T., Tanaka, M., Yamano, M., Shiobara, M., Arao, K. and Nakanishi, Y.: Aerosol optical characteristics in the yellow sand events observed in May, 1982 at Nagasaki-Part II Models, J. Meteorol. Soc. Jpn., Ser. II, 67, 279-291, 1989.

O'Reilly, J. E., Maritorena, S., Mitchell, B. G., Siegel, D. A., Carder, K. L., Garver, S. A., Kahru, M., and McClain, C.: Ocean color chlorophyll algorithms for SeaWiFS, J. Geophys. Res., 103, 24937-24953, 1998.

Ota, Y., Higurashi, A., Nakajima, T., and Yokota, T.: Matrix formulations of radiative transfer including the polarization effect in a coupled atmosphere-ocean system, J. Quant. Spectrosc. Ra., 111, 878-894, 2010.

Ottaviani, M., Knobelspiesse, K., Cairns, B., and Mishchenko, M.: Information content of aerosol retrievals in the sunglint region, Geophys. Res. Lett., 40, 631-634, 2013.

Pan, D. and Z. Mao: Atmospheric correction for China's coastal water color remote sensing, Acta Oceanol. Sin., 20, 343-354, 2001.

Pope, R. M. and Fry, E. S.: Absorption spectrum (380-700 nm) of pure water. II. Integrating cavity measurements, Appl. Optics, 36, 8710-8723, 1997.

Press, W. H.: Numerical Recipes, 2nd Ed.: The Art of Scientific Computing, Cambridge University Press, Cambridge, United Kingdom, 1994.

Quan, X. and Fry, E. S.: Empirical equation for the index of refraction of seawater, Appl. Optics, 34, 3477-3480, 1995.

Remer, L. A., Kaufman, Y., Tanré, D., Mattoo, S., Chu, D., Martins, J. V., Li, R.-R., Ichoku, C., Levy, R., and Kleidman, R.: The MODIS aerosol algorithm, products, and validation, J. Atmos. Sci., 62, 947-973, 2005.

Rodgers, C. D.: Inverse Methods for Atmospheric Sounding: Theory and Practice, World Scientific, Singapore, 2000.

Röttgers, R. D., Doerffer, R., McKee, D., and Schönfeld, W.: Pure Water Spectral Absorbtion, Scattering, and Real Part of Refractive Index Model, ESA Algorithm Technical Basis Document, ESA/ESRIN, Frascati, Italy, 20 pp, 2010.

Ruddick, K. G., Ovidio, F., and Rijkeboer, M.: Atmospheric correction of SeaWiFS imagery for turbid coastal and inland waters, Appl. Optics, 39, 897-912, 2000.

Schroeder, T., Behnert, I., Schaale, M., Fischer, J., and Doerffer, R.: Atmospheric correction algorithm for MERIS above case-2 waters, Int. J. Remote Sens., 28, 1469-1486, 2007.

Sekiguchi, M. and Nakajima, T.: A $k$-distribution-based radiation code and its computational optimization for an atmospheric general circulation model, J. Quant. Spectrosc. Ra., 109, 2779-2793, 2008.

Shettle, E. P. and Fenn, R. W.: Models for the Aerosols of the Lower Atmosphere and the Effects of Humidity Variations on Their Optical Properties, Air Force Geophysics Laboratory, Hanscom Air Force Base, Mass., 1979. 
Shi, C. and Nakajima, T.: Estimation of chlorophyll concentration in waters near Hokkaido using the linear combination method, Opt. Express, 25, A963-A979, 2017.

Shi, C., Wang, P., Nakajima, T., Ota, Y., Tan, S., and Shi, G.: Effects of ocean particles on the upwelling radiance and polarized radiance in the atmospheric-ocean system, Adv. Atmos. Sci., 32, 1-11, 2015.

Shi, C., Nakajima, T., and Hashimoto, M.: Simultaneous retrieval of aerosol optical thickness and chlorophyll concentration from multi-wavelength measurement over East China Sea, J. Geophys. Res.-Atmos., 121, 14084-14101, 2016.

Siegel, D. A., Wang, M., Maritorena, S., and Robinson, W.: Atmospheric correction of satellite ocean color imagery: the black pixel assumption, Appl. Optics, 39, 3582-3591, 2000.

Smith, R. C. and Baker, K. S.: Optical properties of the clearest natural waters (200-800 nm), Appl. Optics, 20, 177-184, 1981.

Stamnes, K., Li, W., Yan, B., Eide, H., Barnard, A., Pegau, W. S., and Stamnes, J. J.: Accurate and self-consistent ocean color algorithm: simultaneous retrieval of aerosol optical properties and chlorophyll concentrations, Appl. Optics, 42, 939-951, 2003.

Steinmetz, F., Deschamps, P.-Y., and Ramon, D.: Atmospheric correction in presence of sun glint: application to MERIS, Opt. Express, 19, 9783-9800, https://doi.org/10.1364/oe.19.009783, 2011.

Stumpf, R., Arnone, R., Gould, R., Martinolich, P., and Ransibrahmanakul, V.: A partially coupled ocean-atmosphere model for retrieval of water-leaving radiance from SeaWiFS in coastal waters, NASA Tech. Memo, 206892, NASA Goddard Space Flight Center, Greenbelt, Maryland, 51-59, 2003.

Takemura, T., Okamoto, H., Maruyama, Y., Numaguti, A., Higurashi, A., and Nakajima, T.: Global three-dimensional simulation of aerosol optical thickness distribution of various origins, J. Geophys. Res.-Atmos., 105, 17853-17873, https://doi.org/10.1029/2000JD900265, 2000.

Takenaka, H., Nakajima, T. Y., Higurashi, A., Higuchi, A., Takamura, T., Pinker, R. T., and Nakajima, T.: Estimation of solar radiation using a neural network based on radiative transfer, J. Geophys. Res., 116, D08215, https://doi.org/10.1029/2009JD013337, 2011.

Tan, S. C., Shi, G. Y., Shi, J. H., Gao, H. W., and Yao, X.: Correlation of Asian dust with chlorophyll and primary productivity in the coastal seas of China during the period from 1998 to 2008, J. Geophys. Res., 116, G02029, https://doi.org/10.1029/2010JG001456, 2011.

Tassan, S.: Local algorithms using SeaWiFS data for the retrieval of phytoplankton, pigments, suspended sediment, and yellow substance in coastal waters, Appl. Optics, 33, 2369-2378, 1994.

Wang, M.: The Rayleigh lookup tables for the SeaWiFS data processing: accounting for the effects of ocean surface roughness, Int. J. Remote Sens., 23, 2693-2702, 2002.

Wang, M.: Atmospheric correction for remotely-sensed oceancolour products, Reports and Monographs of the International Ocean-Colour Coordinating Group (IOCCG), IOCCG, Darmouth, Canda, 2010.
Wang, M. and Bailey, S. W.: Correction of sun glint contamination on the SeaWiFS ocean and atmosphere products, Appl. Optics, 40, 4790-4798, 2001.

Wang, M. and Franz, B. A.: Comparing the ocean color measurements between MOS and SeaWiFS: a vicarious intercalibration approach for MOS, IEEE T. Geosci. Remote, 38, 184-197, 2000.

Wang, M. and Shi, W.: The NIR-SWIR combined atmospheric correction approach for MODIS ocean color data processing, Opt. Express, 15, 15722-15733, 2007.

Xu, F., Dubovik, O., Zhai, P.-W., Diner, D. J., Kalashnikova, O. V., Seidel, F. C., Litvinov, P., Bovchaliuk, A., Garay, M. J., van Harten, G., and Davis, A. B.: Joint retrieval of aerosol and waterleaving radiance from multispectral, multiangular and polarimetric measurements over ocean, Atmos. Meas. Tech., 9, 28772907, https://doi.org/10.5194/amt-9-2877-2016, 2016.

Yan, B., Stamnes, K., Li, W., Chen, B., Stamnes, J. J., and Tsay, S.C.: Pitfalls in atmospheric correction of ocean color imagery: how should aerosol optical properties be computed?, Appl. Optics, 41, 412-423, 2002.

Yoshida, M., Murakami, H., Mitomi, Y., Hori, M., Thome, K. J., Clark, D. K., and Fukushima, H.: Vicarious calibration of GLI by ground observation data, IEEE T. Geosci. Remote, 43, 2167 2176, 2005.

Zhai, P.-W., Hu, Y., Chowdhary, J., Trepte, C. R., Lucker, P. L., and Josset, D. B.: A vector radiative transfer model for coupled atmosphere and ocean systems with a rough interface, J. Quant. Spectrosc. Ra., 111, 1025-1040, 2010.

Zhai, P.-W., Hu, Y., Winker, D. M., Franz, B. A., Werdell, J., and Boss, E.: Vector radiative transfer model for coupled atmosphere and ocean systems including inelastic sources in ocean waters, Opt. Express, 25, A223-A239, 2017.

Zhang, X. and Hu, L.: Estimating scattering of pure water from density fluctuation of the refractive index, Opt. Express, 17, 16711678, https://doi.org/10.1364/oe.17.001671, 2009.

Zhang, X., Hu, L., and He, M.-X.: Scattering by pure seawater: effect of salinity, Opt. Express, 17, 5698-5710, https://doi.org/10.1364/oe.17.005698, 2009.

Zhao, F. and Nakajima, T.: Simultaneous determination of waterleaving reflectance and aerosol optical thickness from Coastal Zone Color Scanner measurements, Appl. Optics, 36, 69496956, 1997.

Zibordi, G., Mélin, F., Berthon, J.-F., Holben, B., Slutsker, I., Giles, D., D'Alimonte, D., Vandemark, D., Feng, H., and Schuster, G.: AERONET-OC: a network for the validation of ocean color primary products, J. Atmos. Ocean. Tech., 26, 1634-1651, 2009.

Zibordi, G., Mélin, F., Voss, K. J., Johnson, B. C., Franz, B. A., Kwiatkowska, E., Huot, J.-P., Wang, M., and Antoine, D.: System vicarious calibration for ocean color climate change applications: requirements for in situ data, Remote Sens. Environ., 159, 361369, 2015. 